\title{
Sustainable management of the vine mealybug in organic vineyards
}

\author{
Arturo Cocco ${ }^{1}$ - Vitor Cezar Pacheco da Silva ${ }^{2}$. Giovanni Benelli $i^{3}$ - Marcos Botton ${ }^{4} \cdot$ Andrea Lucchi $^{3}$. \\ Andrea Lentini ${ }^{1}$
}

Received: 24 March 2020 / Revised: 13 November 2020 / Accepted: 20 November 2020 / Published online: 30 December 2020

(c) The Author(s) 2020

\begin{abstract}
The vine mealybug (VMB), Planococcus ficus, is a major grapevine pest worldwide, whose chemical control is often unsatisfactory due to its cryptic behavior, insecticide resistance and high fecundity rate. Recently, increasing restrictions have been applied to insecticides used for managing VMB. This review discusses sustainable VMB management strategies in organic viticulture. Pheromone-mediated mating disruption has been proved to be effective in both organic wine and table-grape vineyards. Biocontrol projects carried out through the release of parasitoids and/or predators have often provided inconclusive results, ranging from effective reduction of mealybug infestation to a marginal impact of parasitoids on VMB density. The latter outcome is likely due to constraints affecting the parasitoid activity, such as the disrupting activity of mealybug-tending ants and broad-spectrum insecticides, or untimely release of parasitoids. Ant suppression should be associated with the release of beneficial organisms, as mealybug-tending ants can severely affect the parasitoid activity. Cultural and physical control and the employment of entomopathogens and natural products mitigate the buildup of VMB populations, but they are not widely applied. VMB control in organic viticulture requires the integration of different strategies, as application of single control tools as a stand-alone treatment may not be effective, especially for high pest infestation. Future research to determine the density action threshold below which sustainable methods are effective and calibrate efforts in relation with pest infestation is needed. A multi-disciplinary approach is required to define the most appropriate sustainable control protocols in different environmental conditions and promote a further spread of organic viticulture.
\end{abstract}

Keywords Planococcus ficus · Grapevine $\cdot$ Cultural control $\cdot$ Physical control $\cdot$ Biological control $\cdot$ Mating disruption

\section{Key message}

- The vine mealybug (VMB) is a major grapevine pest worldwide.

Communicated by Nicolas Desneux.

Giovanni Benelli

giovanni.benelli@unipi.it

1 Department of Agricultural Sciences, University of Sassari, viale Italia 39, 07100 Sassari, Italy

2 Agronomy Faculty, Department of Plant Protection, University of the Republic, Montevideo, Uruguay

3 Department of Agriculture, Food and Environment, University of Pisa, via del Borghetto 80, 56124 Pisa, Italy

4 Brazilian Agricultural Research Corporation (Embrapa), Bento Gonçalves, Brazil
- Hazardous synthetic insecticides cannot be employed in organic agriculture and are often ineffective.

- Pesticide-free control tactics for VMB encompass biological, cultural and physical control tools including mating disruption and natural products use.

- Mating disruption is among the most commonly applied biorational control tactics.

- VMB control in organic viticulture urgently requires the integration of different available ecofriendly effective strategies.

\section{Introduction}

The vine mealybug (VMB), Planococcus ficus (Signoret) (Hemiptera: Pseudococcidae) (Fig. 1), is a key grape pest in the most important grape-growing regions of the world (Argentina, California, Europe, Mediterranean Africa, Mexico, the Near and Middle East and South Africa) (Daane 
Fig. 1 The vine mealybug, Planococcus ficus: a colony of young females (note the attending ant Crematogaster scutellaris promoting P. ficus infestation through a trophobiotic relationship), b adult male, c male pupa and $\mathbf{d}$ male pupal cocoons (photograph credit a: A. Lucchi, b-d: P. Giannotti)
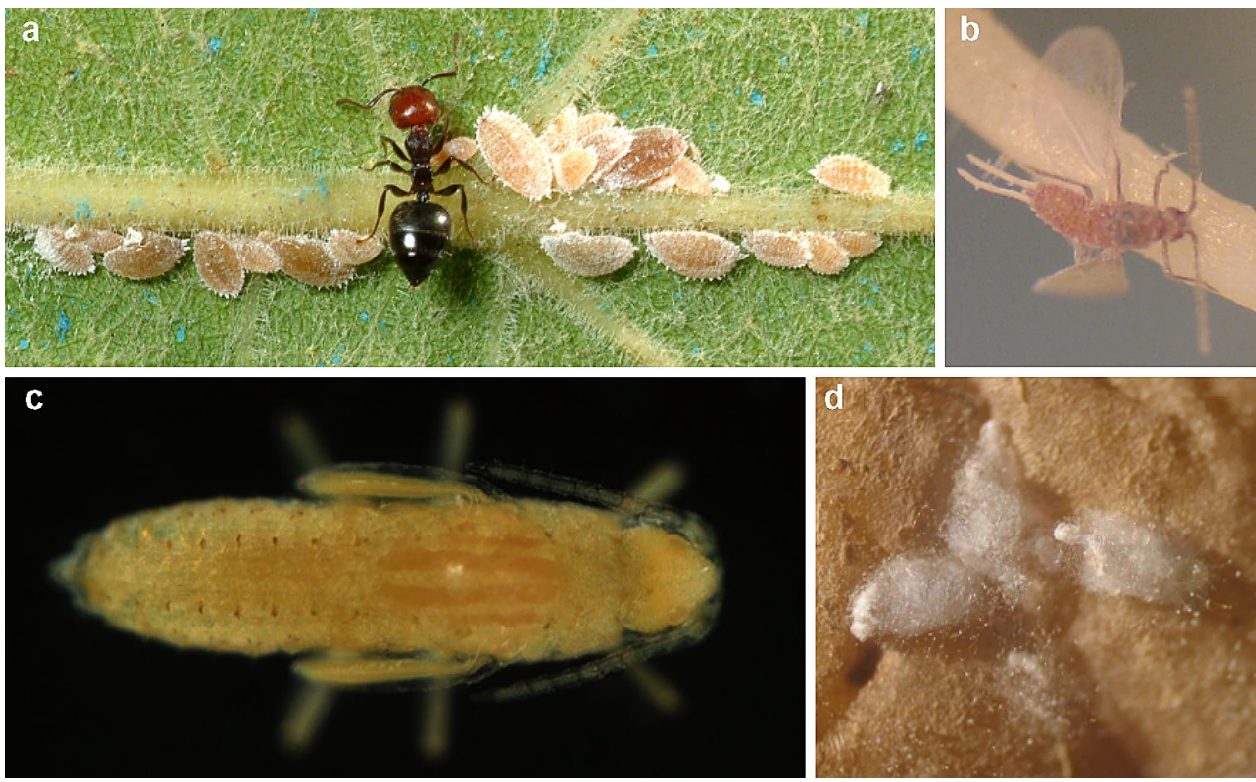

et al. 2008a, 2012). The recent establishment and spread of P. ficus in Brazil (Pacheco da Silva et al. 2016, 2017) indicate this mealybug as a dangerous invasive species in grape-growing areas worldwide (Daane et al. 2012).

VMB causes direct damage to grapevines by depleting large amount of sap, resulting in early leaf fall, dieback and weakening of young plants to death (Walton et al. 2004). The presence of juveniles and females on the grapes also affects negatively the quality of wines (Bordeu et al. 2012). In fact, berries damaged by VMB appear dehydrated and show a higher infection by the ochratoxigenic fungi Aspergillus section Nigri, with consequent potential risk of ochratoxin A occurrence in the wine production chain (Chiotta et al. 2010). Indirect damage is due to the abundant production of honeydew, over which sooty mold fungi develop encrusting leaves and clusters. Thick layers of sooty mold result in a significant reduction of net photosynthesis and an increased temperature of the abaxial leaf surface (Wood et al. 1988). Furthermore, sooty mold and mealybug colonies severely impact the aesthetic quality of table grape, thereby reducing its market value.

This pest is an effective vector of the Grapevine leafroll-associated viruses GLRaV-1, 3, 4, 5 and 9, Kober stem grooving (Grapevine virus A) and corky bark disease (Grapevine virus B) (Tanne et al. 1989; Tsai et al. 2010; Daane et al. 2018a). In particular, the spread of GLRaV-3 in vineyards is rapid and unrelated with the mealybug density, making the mealybug control difficult and necessary even at low population density (Cabaleiro et al. 2008; Charles et al. 2009). A number of studies highlighted that GLRaV-3 affects both red and white wine grape growth and productivity (see Charles et al. 2006 and references therein). Grapevine leafroll-associated viruses significantly depress photosynthesis up to $65 \%$ even in asymptomatic plants, also reducing cane and root growth and stem girth. Other symptoms can be a slowing down of the seasonal phenology, with delayed budbreak and berry ripening, as well as a reduced crop yield over the plant lifetime. With regard to berry quality, GLRaV-3 reduces the sugar content, anthocyanins and $\mathrm{pH}$ and increases the titratable acidity of must obtained by infected grapes. Overall, the reduced grape yield and quality of wine can cause an economic loss up to $74,000 € \mathrm{ha}^{-1}$ in a vineyard lifespan of 30 years (Cabaleiro et al. 2013).

Conventional control programs for VMB in vineyards rely on repeated applications of synthetic insecticides throughout the grape-growing season, including organophosphates and neonicotinoids (Walton et al. 2004, 2006; Daane et al. 2012), which showed both severe non-target effects on bees and pollinators (Mansour et al. 2018). The efficacy of chemical control is variable and often unsatisfactory, as mealybugs reside primarily in concealed locations (i.e., under the bark and in bark crevices) and on the roots up to $30 \mathrm{~cm}$ deep (Walton and Pringle 2004a; Walton et al. 2004; Daane et al. 2012; Sharon et al. 2016) protected from contact insecticides. More recently, the systemic insecticide spirotetramat, a lipid biosynthesis inhibitor, was effective in controlling $P$. ficus with no adverse side effects on non-target fauna (Brück et al. 2009; Mansour et al. 2018). Therefore, this active substance has been successfully included in insecticide-based control programs (Mansour et al. 2010a).

Chemical insecticide-based control of VMB has shown a number of constraints, which have been extensively reviewed by Mansour et al. (2018). The repeated use of insecticides with the same mode of action could lead to the development of resistant populations (Venkatesan et al. 2016) and pose a significant constraint in mealybug management programs. 
Several ineffective control programs against mealybugs have been attributed to insecticide resistance (Franco et al. 2004; Charles et al. 2006), and VMB possibly developed resistance to the organophosphate methidation (Mansour et al. 2010a). In addition, VMB populations collected in California showed widely different baseline susceptibility to insecticides, such as buprofezin (sevenfold variability), imidacloprid (8.5-fold) and chlorpyrifos (11-fold) (Prabhaker et al. 2012). These compounds are three of the most common insecticides used worldwide in conventional control programs against $P$. ficus. Imidacloprid, chlorpyrifos-methyl and chlorpyrifos could also disrupt the activity of natural enemies (via multiple side effects, e.g. see Desneux et al. 2007), notably Anagyrus pseudococci (Girault), Anagyrus vladimiri Triapitsyn [ex Anagyrus sp. near pseudococci (Girault)], Coccidoxenoides perminutus Girault (Hymenoptera: Encyrtidae) and the mealybug destroyer, Cryptolaemus montrouzieri Mulsant (Coleoptera: Coccinellidae) (Mansour et al. 2011a; Planes et al. 2013; Mgocheki and Addison 2015). Moreover, the non-rational and excessive use of pesticides may result in environmental pollution. Imidacloprid and chlorpyrifos were detected, together with other pesticides, in ground and surface waters in the grapegrowing region of La Rioja (Spain), concurring to water contamination (sum of pesticides $>0.5 \mu \mathrm{g} \mathrm{L}^{-1}$ according to EU legislation) (Herrero-Hernandez et al. 2013, 2017). Finally, the presence of insecticide residues in grapes may affect the fermentation process by selecting different yeast strains (Caboni and Cabras 2010).

The latest policies on commercialization of plant protection products at national and transnational level have been directed toward high levels of food safety, protection to human and animal health and environmental safeguard (Regulation 1107/2009/EC) (European Union 2009a). In accordance with this action plan, the Directive 2009/128/ EC promotes the sustainable use of pesticides and encourages the introduction of control techniques, including physical, mechanical and biological control methods, as alternative to chemical insecticides (European Union 2009b). Recently, severe limitations have been adopted in Europe through the Regulations 2018/783, 2018/784 and 2018/785 regarding the open-field application of imidacloprid, clothianidin and thiamethoxam, respectively (European Union 2018a, b, c), which have been widely used to control VMB. Chlorpyrifos and chlorpyrifos-methyl have been withdrawn from use in Europe since early 2020 because of concerns related to human health, namely possible genotoxicity and developmental neurotoxicity (European Union 2020a, b), whereas their use in California will cease at the end of 2020 (CDPR 2020). Legislation on the use of insecticides also varies among European countries, as, for example, the insect growth regulator buprofezin, which has been banned in vineyards in Italy (Italian Ministry of Health 2020).
The grape industry is continuously expanding worldwide, with vineyards extended over almost $7.1 \mathrm{mHa}$ and an estimated total export value of 7.8 billion $\$$ (data referred to 2016, FAOSTAT 2018). In this framework, organic viticulture is a well-established sector, being spread worldwide on almost 380,000 ha (5.3\% of the total grape-growing area) (Lernoud and Willer 2018). A noticeable increase in the grape supply is further expected in the next years, since about $30 \%$ of the organic grape area is still in conversion from conventional viticulture. Sustainable viticulture has developed since the early 1990s, increasing by 4.3 -fold in the period 2004-2016 (Lernoud and Willer 2018). Nowadays, organic vineyards are mainly located in Europe (90\%) where they represent $8.3 \%$ of the grape area, especially in Spain, Italy and France $(11.6 \%, 15.5 \%$ and $9.3 \%$ of total grape area, respectively). The increasing demand of sustainable and environmentally friendly crop production systems can be met through the development and implementation of effective sustainable management systems in vineyards.

The present review provides an up-to-date and complete overview of the available control tactics (biological, cultural and physical control tools, natural compounds and mating disruption), as well as basic information on VMB biology that deeply influences the effectiveness of control tactics. The key factors that affect the sustainable control of VMB are critically discussed to implement comprehensive and effective management programs. Finally, future perspectives will explore opportunities and constraints for developing environmentally safe strategies and promote a further spread of organic viticulture.

\section{The vine mealybug Planococcus ficus}

\section{Morphology and species discrimination}

Vineyard mealybugs of primary importance worldwide are the vine mealybug P. ficus, the grape mealybug Pseudococcus maritimus (Ehrhorn), the obscure mealybug Pseudococcus viburni (Signoret), and the longtailed mealybug Pseudococcus longispinus (Targioni-Tozzetti) (Hemiptera: Pseudococcidae). These species have different geographic ranges, due to different climatic requirements and to isolation among world grape-growing regions, even though their worldwide distributions partially overlap (García Morales et al. 2016) (Fig. 2). Other mealybugs are locally important: the citrus mealybug Planococcus citri (Risso) and the pink pineapple mealybug Dysmicoccus brevipes (Cockerell) in Brazil, the citrophilus mealybug Pseudococcus calceolariae (Maskell) in New Zealand, the Gill's mealybug Ferrisia gilli Gullan in California and the pink hibiscus mealybug Maconellicoccus hirsutus (Green) in India and northeastern Brazil (Daane et al. 2012; Oliveira et al. 2018). 
Fig. 2 Worldwide distribution of the most common vineyard mealybugs: a vine mealybug Planococcus ficus, b longtailed mealybug Pseudococcus longispinus, c grape mealybug Pseudococcus maritimus and $\mathbf{d}$ obscure mealybug Pseudococcus viburni (García Morales et al. 2016)
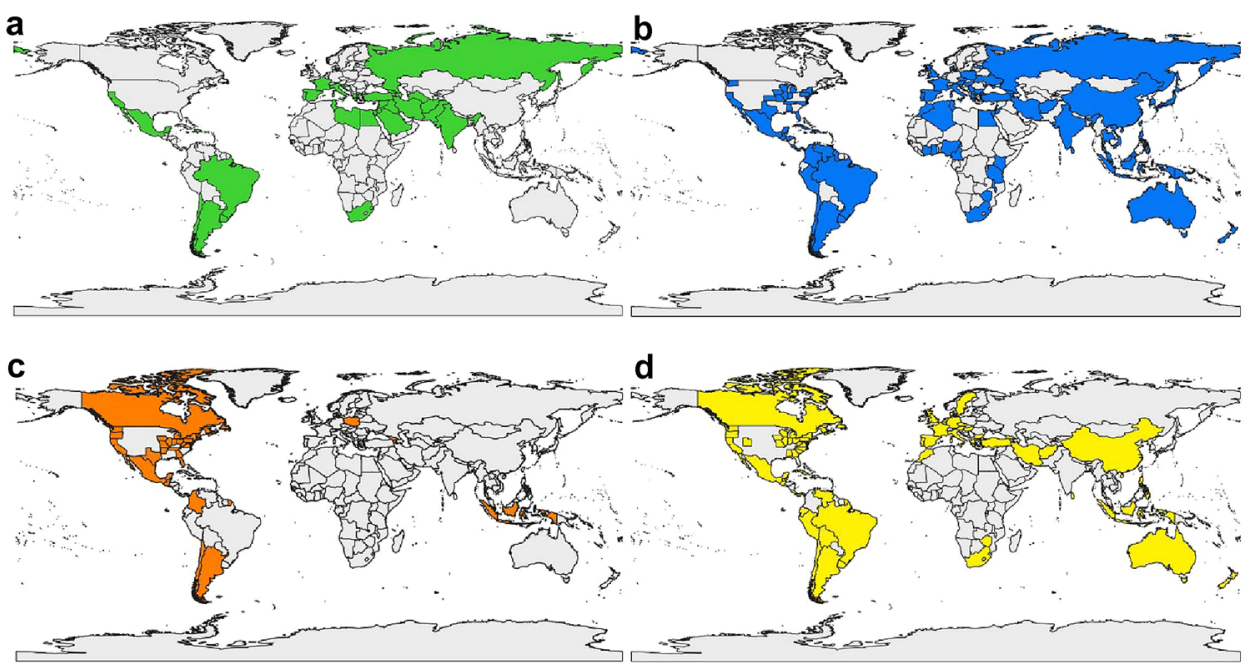

Discrimination of mealybug species infesting grapes is of crucial importance for quarantine purposes, to avoid further spread of these pests. In addition, species identification guides species-specific control measures, such as mating disruption and biological control. Finally, mealybugs showed a different efficiency to vector a range of grapevine diseases, including GLRaVs, Grapevine virus A (GVA) and Grapevine virus B (GVB) (Tsai et al. 2010; Bertin et al. 2016). All these aspects emphasize the importance of an accurate identification of vineyard mealybugs.

Microscopic preparations are indispensable for mealybug identification, although the main genera of vineyard-associated species can be distinguished visually. Mealybugs are so-called due to the presence of white powdery wax coating the surface of the body and, when present, the waxy filaments arranged at the body margins (Williams and Granara de Willink 1992). Planococcus species show an elliptical body shape with short lateral filaments, with those present in the anal region of the body poorly distinguished from the others (differentiating them from Pseudococcus species). Moreover, a median longitudinal strip is present on the dorsum, due to the limited deposition of waxes in this region.

The genus Planococcus includes 48 species (García Morales et al. 2016) divided by Cox (1989) into five informal groups. The citri-group includes the species of main economic importance, such as the sibling species $P$. citri, $P$. ficus, $P$. minor (Maskell) and P. halli Ezzat and McConnell (Hemiptera: Pseudococcidae) (Cox 1989). Planococcus species are not easy to be distinguished due to the lack of discriminant characters in the adult female (1989) and intraspecific morphological variations in the taxonomic characters (Cox and Wetton 1988; Ben-Dov and Matile-Ferrero 1995). Therefore, some species, such as $P$. citri and $P$. minor, or $P$. ficus and $P$. halli, can only be distinguished morphologically by a matrix to be scored using a point system (Cox 1989), although Rung et al. (2008) observed that the score is not
$100 \%$ reliable, based on molecular characterization of the specimens.

In order to overcome difficulties in the early identification of grapevine mealybugs, several species-specific molecular protocols have been developed, mostly based on species differences within the nuclear DNA 28S-D2 and internal transcribed spacer 2 (ITS2), the $16 \mathrm{~S}$ region located in the DNA of the primary endosymbionts, Tremblaya princeps, the nuclear elongation factor 1 alpha $(\mathrm{EF}-1 \alpha)$, and mostly the mitochondrial gene cytochrome $c$ oxidase I (COI) amplified through polymerase chain reaction (PCR) (Demontis et al. 2007; Cavalieri et al. 2008; Rung et al. 2008; Saccaggi et al. 2008; Daane et al. 2011; Malausa et al. 2011; Pacheco da Silva et al. 2014).

A molecular analysis of VMB populations from grapegrowing regions worldwide highlighted the existence of two broad populations: a European group (Europe, Tunisia, Turkey) and a Middle Eastern group (Israel and Egypt) (Daane et al. 2018b). The study shed light on the pathways of introduction of VMB from the native geographic range (Europe-North Africa-Middle East) to newly invaded areas. In fact, the invasive populations established in Argentina and South Africa belong to the European group, whereas populations infesting North American and Mexican vineyards align with the Middle Eastern group, in particular with an Israeli population.

\section{Development and reproduction}

VMB is adaptable to different climatic conditions from semiarid to subtropical areas or cool continental climates, and it is characterized by a high reproductive potential under optimal temperature (Walton and Pringle 2005). It can complete three-four generations per year in Italy, five-six in South Africa and Argentina, and up to ten generations per year in California and Israel (Daane et al. 2012; Sharon et al. 2017). 
Temperature is the main factor affecting the development of $P$. ficus. The threshold temperatures for VMB development have been investigated under laboratory conditions. The lower and upper developmental thresholds were determined to be $16.6{ }^{\circ} \mathrm{C}$ and $35.6{ }^{\circ} \mathrm{C}$, respectively, on potted grape seedlings (Walton and Pringle 2005) and $14.3{ }^{\circ} \mathrm{C}$ and $32.5^{\circ} \mathrm{C}$, respectively, on excised leaves replaced daily (Varikou et al. 2010). The optimal temperature for development was of $27-28{ }^{\circ} \mathrm{C}$ in both studies, whereas the shortest egg-to-adult developmental time ranged from 23.2 days (Walton and Pringle 2005) to 39.9 days (Varikou et al. 2010) at $30{ }^{\circ} \mathrm{C}$. Differences in the biological outcomes could be due to the different cultivars used as feeding substrate (Soultanina, Waltham Cross) and the different rearing methods, since repeated handling of mealybugs when replacing excised leaves could disrupt or alter the immature development (Varikou et al. 2010). Possible genetic differences between populations hypothesized by Varikou et al. (2010) have been ruled out by molecular analysis of VMB populations worldwide, with South African, Argentinian and Greek populations belonging to the same European group (Daane et al. 2018b). Another abiotic factor involved in the development and reproduction output of $P$. ficus is the nitrogen; in fact, mealybugs exhibited a decreasing developmental time at increasing nitrogen content on leaves, either due to higher nitrogen fertilization regimes or complete legume cover crops (Cocco et al. 2015; Muscas et al. 2017). Developmental times also differed within the same multi-year field experiment, indicating the influence of annual climatic conditions (Muscas et al. 2017).

VMB females only reproduce sexually, although unmated females are capable of producing ovisacs and unviable eggs (Waterworth et al. 2011; A. Lentini unpubl. data) and parthenogenetic reproduction has never been reported. Reproduction is mediated by the specific sex pheromone, $(S)-(+)$-lavandulyl senecioate (Hinkens et al. 2001; Tabata 2020), and a second active component, ( $S$ )-lavandulyl isovalerate, has been recorded later in Israeli populations (Zada et al. 2003). Further studies defined the existence of nine male pherotypes in Israel and five in Portugal, according to male attraction, repulsion, or indifference to the two pheromone components (Kol-Maimon et al. 2010). Differences in the production of a sex pheromone blend and response to pheromone stimuli may be due to the existence of different VMB populations (Daane et al. 2018b). Pheromone release by females and male flight are synchronized and restricted to 2-4 h after sunrise (Zada et al. 2008; LeviZada et al. 2014).

VMB showed under laboratory conditions a polygamous mating system, as females and males can mate multiple times (Waterworth et al. 2011). Constant exposure of males to sex pheromone did not affect the female search after eclosion (Waterworth et al. 2011). These traits have important implications in management programs. In fact, the obligate sexual reproduction allows the application of pheromonemediated control tactics, such as mating disruption, while in turn virgin females are long living and are able to call for males and mate in a long time period. In view of these factors, mating disruption, to be effective, would constantly disrupt the male-female sexual communication throughout the season.

The fecundity of VMB females is reported by several studies, which have been carried out under different experimental conditions of temperature, feeding substrate, cultural practices and control techniques (Walton and Pringle 2005; Walton et al. 2006; Waterworth et al. 2011; Gonzalez Luna and La Rossa 2016; Muscas et al. 2017; Cocco et al. 2018a, b; Lentini et al. 2018). Overall, females oviposit 200-300 eggs and up to more than 400 eggs, with the highest fecundity being observed in the temperature range of $20-27{ }^{\circ} \mathrm{C}$ and sharp reductions at more extreme temperatures (Walton and Pringle 2005). Annual climatic conditions (Muscas et al. 2017; Cocco et al. 2018a, b), nitrogen concentration on leaves, either caused by fertilization or cover crops (Cocco et al. 2015; Muscas et al. 2017), and the grape cultivar (Gonzalez Luna and La Rossa 2016) further affect the number of oviposited eggs. On the other hand, the fecundity of females is not affected by the number of copulations, female age at mating and mating delay due to mating disruption control technique (Waterworth et al. 2011; Cocco et al. 2018b; Lentini et al. 2018). The daily oviposition pattern under laboratory conditions on females mated within 7 days showed a peak of about 30 eggs per day reached 5-7 days after the beginning of oviposition, whereas females mated at 14-28 days old reached oviposition peaks $>50$ eggs per day in 4-5 days (Lentini et al. 2018).

Fertility of VMB females under natural and semi-field conditions was higher than $90 \%$, and climatic conditions and cultural practices (e.g., nitrogen fertilization, cover crop) had no or limited influence on egg eclosion (Cocco et al. 2015, 2018a, b; Muscas et al. 2017). The mating disruption control tactic also affected the female fertility, although the reduction was $<2 \%$ and not practically significant for control purposes (Cocco et al. 2018b). The sex ratio is female biased (approximately 60\%) (Rotundo and Viggiani 1982; Walton and Pringle 2005; Cocco et al. 2015). Nonetheless, sub-optimal developmental temperatures can decrease the percentage of female offspring (Walton and Pringle 2005), whereas the female age at mating did not affect the sex ratio (Lentini et al. 2018).

Studies on the VMB longevity indicated an overall long lifespan of females which lived for more than 90 days on potato tubers under laboratory and field conditions, whereas in turn males are short-living and survived up to 7.5 days in laboratory trials (Walton and Pringle 2005; Varikou et al. 2010; Waterworth et al. 2011; Gonzalez Luna and La Rossa 
2016; Cocco et al. 2018b). Overall, longevity of both males and females decreased at increasing temperatures (Walton and Pringle 2005; Varikou et al. 2010). Constant exposure of males to sex pheromone did not affect their longevity (Waterworth et al. 2011).

Biological and reproductive parameters described above have also been used to calculate the population growth potential through the assessment of demographic parameters, especially the intrinsic rate of increase $\left(r_{m}\right)$, which accounts of the natural potential of a population to increase in numbers. Under laboratory conditions at $25^{\circ} \mathrm{C}$, the intrinsic rate of increase ranged from 0.11 to 0.17 female per female per day, whereas in the field, on grapevines of cultivar Carignano, $r_{m}$ values varied from 0.06 to 0.08 female per female per day, depending on climatic conditions (Walton and Pringle 2005; Gonzalez Luna and La Rossa 2016; Cocco et al. 2018a; Lentini et al. 2018). The grapevine cultivar affects the VMB development; in fact, VMB populations exhibited a better reproductive performance (i.e., better demographic parameters) when reared on Malbec than on Chardonnay (Gonzalez Luna and La Rossa 2016). A delay of females mating $>7$ days and extreme temperatures $\left(\leq 18^{\circ} \mathrm{C}\right.$ and $\geq 30^{\circ} \mathrm{C}$ ) also caused a significant reduction of the population growth potential (Walton and Pringle 2005; Lentini et al. 2018).

\section{Seasonal phenology}

The major mealybug species infesting grapevines, especially P. ficus, P. maritimus and P. viburni, exhibit a distinctive upward seasonal movement from overwintering sites to the canopy. However, the seasonal phenology differs depending on endogenous (specific thigmotactic behavior) and exogenous factors (temperature and vineyard management practices) (Geiger and Daane 2001; Becerra et al. 2006; Cid et al. 2010). Also, as different species have different numbers of annual generations and preferred feeding locations throughout the season, sampling procedure and control programs should be tailored specifically to the mealybug species. Knowledge of the seasonal pest abundance and distribution of VMB allows to develop effective monitoring programs, in order to search mealybugs in the plant organs where they are more likely to be found. Furthermore, information on the seasonal movement along the plant is of great practical importance to growers and technicians to plan timely insecticide applications when the most susceptible mealybug instar, i.e., crawlers, are exposed.

\section{Seasonal abundance}

The VMB population density is lowest in the winter months, when mealybugs overwinter under the bark of trunk and cordons or on the roots (Daane et al. 2003; Walton 2003;
Lentini et al. 2008). Overall, the population density increases steadily in spring reaching the highest seasonal abundance immediately preceding or concurrently grape ripening, in April in a desert climate such as Coachella Valley (California) or in August in temperate areas such as southern Italy or San Joaquin Valley (California) (Daane et al. 2003; Lentini et al. 2008). In the Southern Hemisphere (South Africa), peaks of infestation have been observed in January-February, with mealybugs mostly infesting bunches (Le Vieux and Malan 2013). After grape harvest, and concurrently with unfavorable climatic conditions, the population density rapidly declines and remains low but steady in winter.

\section{Seasonal movement and within-plant distribution}

Planococcus ficus overwinters in concealed locations under the bark, mainly in the upper part of the trunk or along the cordon. In the Northern Hemisphere (Italy), mealybugs mostly overwinter in the trunk and cordons as well as under the bark of canes and spurs (Duso 1989; Lentini et al. 2008), and the VMB seasonal activity is concurrent with grape bud burst, when mealybugs start moving from overwintering locations to the base on new shoots (Fig. 3a). Since April, mealybugs spread and settle on the canopy, while a relevant percentage of the pest population still reside under the trunk bark (20-25\% in July-August). In late summer, mealybugs infest ripening bunches, settling mainly in the inner parts (rachis, pedicels). From October, concurrently with canopy senescence, VMB mostly moves back to woody plant organs (Fig. 3a). In grape-growing areas of California with Mediterranean climatic conditions (San Joaquin Valley), seasonal movement shows the same pattern starting from March, whereas, in a desert table-grape growing region (Coachella Valley), mealybugs are mostly exposed on leaves and bunches concurrently with ripening (May-June) and move to lower trunk and roots during the hottest months (July-September) (Daane et al. 2003). Under such hot climate, mealybugs were observed on roots and trunk throughout the year.

In the Southern Hemisphere (Argentina), mealybugs overwinter mostly in the egg stage in the lower portion of the trunk, moving gradually toward the upper part of the trunk since September, reaching branches, canes and leaves in November and up to bunches in December (Becerra et al. 2006). In January-February, mealybugs are dispersed in the whole canopy and migrate back under the bark from late March to late April.

The VMB population structure changes throughout the year according to climatic conditions and plant phenology. In southern Italy in winter (December-February), adult female was the most abundant stage, with a gradual increase of females with ovisacs since January (Fig. 3b). The crawler density peaked between mid-April and mid-May before 
Fig. 3 a Percent distribution of Planococcus ficus mealybugs on wine grape and $\mathbf{b}$ seasonal distribution of $P$. ficus developmental stages. Shaded areas indicate the periods of peak in crawler abundance (modified from Lentini et al. 2008, Sardinia, Italy)

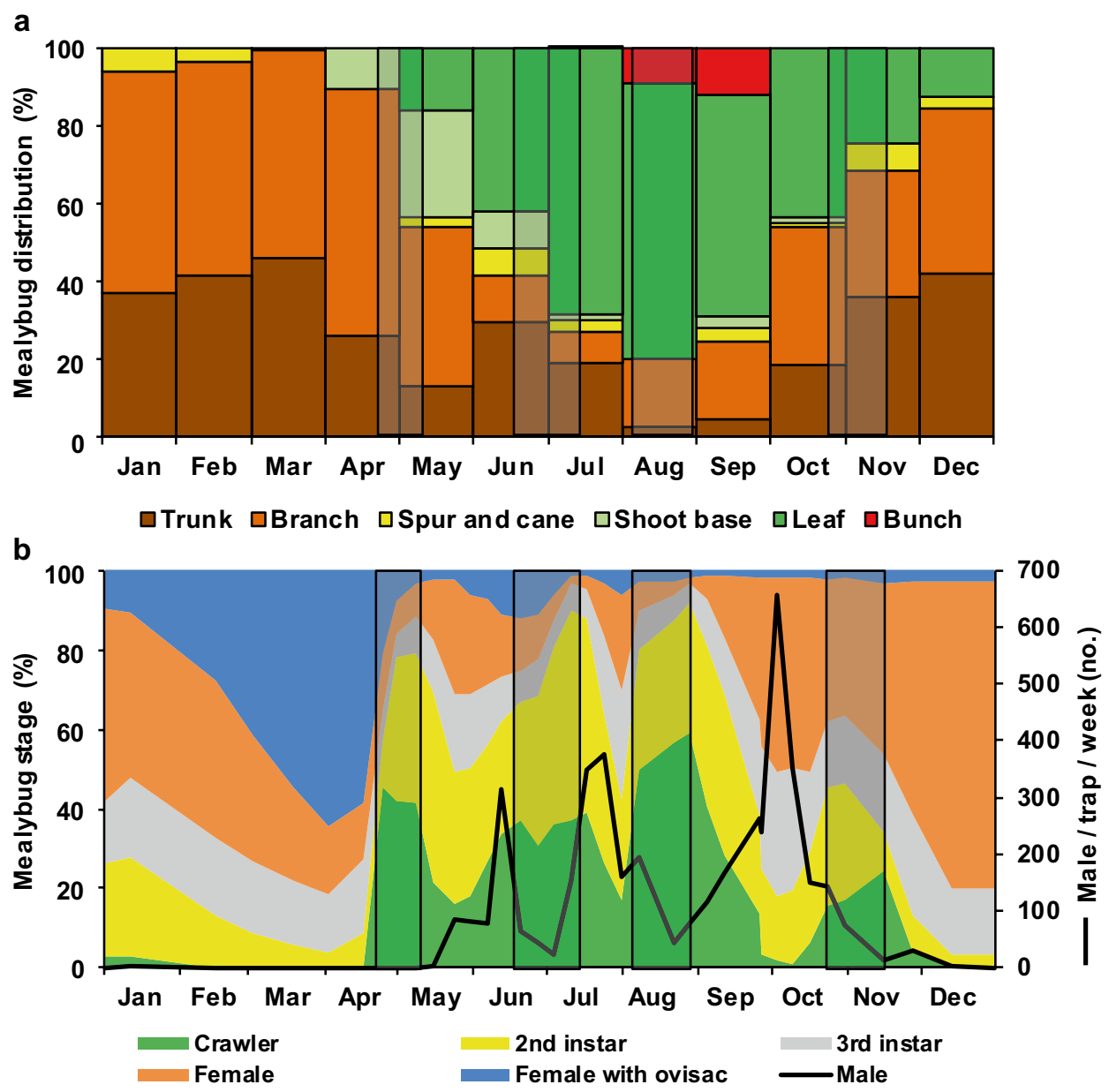

male flight activity, which started in mid-May, indicating that females mostly overwintered after mating. The following peaks of crawler abundance occurred in mid-June-midJuly, August and mid-October-November, each one after a peak in male captures in pheromone traps, for a total of four annual generations. The massive spread of colonization of the grape canopy by VMB coincides with peaks of crawlers, which are the most mobile mealybug stage.

The spread in the canopy also follows a distinctive pattern, as immatures migrating toward the canopy in spring-early-summer settled mainly on axillary shoots, i.e., suckers, and following migrations settled mainly on proximal shoots with a decreasing density gradient along the shoot (Lentini et al. 2008). In August, mealybugs were mostly located between the second and the fifth node, mainly on bunches and opposite leaves, so that the second cluster on the first shoot and the opposite leaf was indicated as the optimal sample unit for monitoring the mealybug population dynamics on grape (Duso 1989). Overall, mealybug infestation in cane-pruned grapevines gradually decreased on shoots along the cane (Lentini et al. 2008).

\section{In-field distribution of Planococcus ficus}

The VMB distribution in vineyards is clumped, as indicated by investigations with dispersion index (Taylor's power law) (Duso 1989). More recent spatial analysis studies carried out with SADIE (Spatial Analysis by Distance IndicEs) highlighted an aggregated spatial pattern in 50 and $90 \%$ of the investigated vineyards in South Africa and Italy, respectively (Mgocheki and Addison 2010; Cocco et al. 2018b). It implies that mealybugs spread from highly infested hot spots, often along vineyard margins, to surrounding areas. The aggregated pattern of $P$. ficus populations was observed in undisturbed populations and in population in which the male-female communication was altered by mating disruption (Cocco et al. 2018b). The population density also did not seem to affect the pest clumped distribution, which was observed in both low and highly infested plots in Italy (Cocco et al. 2018b), in accordance with findings of Geiger and Daane (2001) on P. maritimus. 


\section{Cultural and physical control}

\section{Cultural control}

In the perspective of a multi-disciplinary approach to pest control, inclusion of cultural practices in IPM programs is gaining importance (e.g. Damien et al. 2017; Michaud 2018; Santoiemma et al. 2020). The tolerance of rootstocks and cultivars to $P$. ficus infestations has been recently investigated in potted plants (Naegele et al. 2020), indicating the cultivars Chardonnay and Cabernet Sauvignon as favorable substrates for VMB population growth, whereas the rootstocks IAC 572, 10-17A and RS-3 reduced the pest development. Naegele et al. (2020) also suggested that physical and/ or chemical features may affect mealybug settling, feeding and host attractiveness, being therefore involved in the resistance mechanisms (antibiosis and antixenosis). However, grapevine plants displayed a weak transcriptional response to $P$. ficus feeding, with a single gene, pathogenesis-related protein 1 , being expressed as a response of mealybug attack (Timm and Reineke 2014).

Improvements in grape yield have been pursued with increasing use over time of nitrogen fertilization, which has, in turn, also promoted VMB infestations. In laboratory and semi-field experiments, potted grapevines supplied with increasing rates of ammonium nitrate exhibited higher nitrogen concentration on leaves (Cocco et al. 2015). Mealybugs reared on high nitrogen-fertilized vines exhibited higher developmental and reproductive performances. In fact, the pre-imaginal development time was inversely correlated with the leaf nitrogen concentration, whereas fecundity, body size and survival were positively correlated. The better performance of VMB fed on high-nitrogen substrates could be due to the higher nutritional value of phloem sap.

Cover cropping is a cultural practice widely adopted in vineyards for many purposes, such as improving soil structure, organic matter and carrying capacity, reducing soil erosion and regulating plant vigor. Complete cover cropping in both intra- and inter-row affected grapevine growth, crop yield and must quality as well as VMB development and reproduction (Muscas et al. 2017). Soil tillage and legume cover crop stimulated the pest development by increasing mealybug survival, fecundity and fertility and reducing the development time. Furthermore, cover crops in vineyards favor the establishment of ant colonies, which promote mealybug infestation and reduce the parasitoid activity (Serra et al. 2006; Mgocheki and Addison 2010). In view of the multiple effects of the ground cover on grape yield and quality and VMB development, there is not a single most suitable floor management practice and generalizations cannot be made, as the optimal choice depends on climatic conditions, soil, grape cultivar, rootstock and oenological goals.
Wooded vegetation along vineyard edges and herbaceous covers around and within vineyards also concur to enhance richness and abundance of parasitoids, such as Trichogramma, and predators, including coccinellids, lacewings, spiders, staphilinids and predatory mites and thrips (Thomson and Hoffman 2009, 2013; Shapira et al. 2018a). The parasitoid fecundity and the encyrtid population growth could be promoted by the presence of wildflower spots and strips in vineyards (Benelli et al. 2017). Indeed, A. vladimiri feeding on flower-borne food sources (e.g., vetch extrafloral nectaries or buckwheat flowers) significantly increased the offspring production when compared with water (Irvin and Hoddle 2015).

Plant architecture have been indicated as affecting VMB infestations (Dalla Montà et al. 2001), in accordance with findings on P. maritimus by Geiger and Daane (2001). These authors observed higher mealybug density and bunch damage on spur-pruned than on cane-pruned grapevines, probably because spur-pruned grapevines retain more old wood and, therefore, more bark for mealybug refuge and protection. Moreover, the canopy architecture of spur-pruned vines favors the development of bunches touching old wood, with a higher likelihood of mealybug colonization on bunches. Summer pruning, especially in organic table-grape vineyards, is directed to remove clusters touching old wood and ensure that they are free-hanging so that mealybugs can infest them only through the stem (D. Haviland, University of California, pers. comm.). Summer pruning, which removes secondary shoots and supernumerary leaves, may concur to reduce VMB population density on the canopy by facilitating the foraging activity of natural enemies and fostering control applications by aerating the canopy (Walton and Pringle 2004b). Debarking of grapevines, also associated with mineral oil applications, was effective in reducing VMB density (Pavlović et al. 2019). The effectiveness of this practice is higher in winter, when the mealybug population mostly resides under the bark and mineral oil can be applied at higher concentration. However, stripping the bark off the trunk is expensive and time-consuming and not applied in commercial vineyards.

\section{Physical control}

The VMB thigmotactic behavior as well as its tiny size makes it difficult the control, facilitating, at the same time, its spread. Regarding the latter, movement of infested cuttings has caused the rapid spread of the pest in California in the early 1990s (Daane et al. 2004c). Several procedures have been developed to sanitize grape cuttings in nurseries, thereby reducing the risk of pest spread and severe infestations in newly planted vineyards. Trials with different combinations of temperatures and immersion periods indicated as optimal procedure a hot-water treatment in three steps 
of five minutes each as follows: pre-heating $\left(30^{\circ} \mathrm{C}\right)$, heating $\left(52,8^{\circ} \mathrm{C}\right)$ and cooling $\left(23^{\circ} \mathrm{C}\right)$ (Haviland et al. 2005). This protocol has been commercially used by nurseries in California for VMB control in dormant grape cuttings, as it provides a mealybug mortality of $99.8-100 \%$ and is also effective against root knot nematodes, grape phylloxera, Daktulosphaira vitifoliae Fitch (Hemiptera: Phylloxeridae) and fungal and bacterial diseases. However, treatments in hot water are labor-intensive and longer immersions or exposure to higher temperature may alter the rooting of grape cuttings. More recently, ultralow oxygen treatments caused $100 \%$ mortality of all stages of $P$. ficus, without reducing the growth of grafted grape cuttings (Liu et al. 2010).

\section{Biological control}

Many natural enemies, mainly insect parasitoids and predators, have been reported as associated with $P$. ficus in vineyards worldwide, some of which are studied for long time (Whitehead 1957; Berlinger 1977). The complete complex of natural enemies reported worldwide on VMB is listed in Table 1. The recent implementation of natural enemy releases within Integrated Pest Management (IPM) programs and biological control enhancement have provided new insights for effective application of this control tactic (Lucchi and Benelli 2018). Lately, also entomopathogens (nematodes, fungi and bacteria) have been tested with promising results.

\section{Parasitoids}

\section{Anagyrus pseudococci (Girault) and Anagyrus vladimiri Triapitsyn (Hymenoptera: Encyrtidae)}

Anagyrus pseudococci s.l. is a koinobiont endoparasitoid widely employed worldwide as a biocontrol agent of mealybugs (Daane et al. 2012). Earlier, Triapitsyn et al. (2007) reported the existence of two morphotypes in populations of A. pseudococci released in Californian biocontrol programs for VMB management. The two morphotypes differed only for the color of the first antennal funicle segment of the female, partially black (basal half) and white (distal half) in A. pseudococci, and entirely black in the other morphotype, which was named $A$. sp. near pseudococci. While the former species is known only from Sicily (Italy), Argentina and Cyprus, the latter has been detected in various Mediterranean countries (including Sicily), Palaearctic Asia, Brazil, USA and South Africa (Triapitsyn et al. 2007; Wohlfarter and Addison 2014). In a recent study by Andreason et al. (2019), A. sp. near pseudococci was redescribed as Anagyrus vladimiri Triapitsyn sp. nov. (Fig. 4a), confirming that this species is present in Israel, Italy, Russia, Spain,
Turkmenistan, California (USA) and Tunisia (Triapitsyn et al. 2007; Mansour et al. 2017a). The authors also pointed out that other records of $A$. pseudococci s.l. (Noyes and Hayat 1994; Triapitsyn 1989) are likely to be referred to $A$. vladimiri, except for reports of females with the first funicle partially black and white (Triapitsyn et al. 2005, 2007).

Biological and reproductive parameters of A. pseudococci s.l. are affected by abiotic factors, with temperature being a key factor in the perspective of effective biological control programs. The optimal developmental temperature of A. vladimiri determined under laboratory conditions ranged from 24.7 to $30.7^{\circ} \mathrm{C}$, whereas lower and upper developmental thresholds were $11.6-16.3$ and about $36{ }^{\circ} \mathrm{C}$, with a thermal constant of 223.5 degree-days (Daane et al. 2004a; Wohlfarter and Addison 2014). Interestingly, laboratory experiments showed that the emergence of overwintering A. vladimiri occurred mainly in early May, regardless of when $P$. ficus hosts were parasitized, suggesting that cues other than temperature concurred to synchronize spring emergence of $A$. vladimiri adults with field availability of P. ficus (Daane et al. 2004a). The optimal temperature for A. vladimiri population growth was determined to be $27^{\circ} \mathrm{C}$, above which the parasitoid showed a higher net reproductive rate than $\mathrm{VMB}$, indicating a reproductive advantage over its host at higher temperatures (Wohlfarter and Addison 2014). In the framework of climate change, A. vladimiri could benefit by increasing temperature and it has been predicted to have a larger impact on VMB if compared to the encyrtid Leptomastidea abnormis (Girault) and the coccinellid $C$. montrouzieri (Gutierrez et al. 2008).

With the aim of achieving successful biological control programs, host-parasitoid interactions of $A$. pseudococci s.l. and P. ficus have been investigated in several studies (Güleç et al. 2007; Franco et al. 2008; Suma et al. 2012). Despite a rather broad host range (see Triapitsyn et al. 2007), host acceptance of $A$. vladimiri differed significantly among Pseudococcidae host species, showing a clear preference for P. ficus (Bugila et al. 2014a). In response to parasitization, VMB exhibited a peculiar defensive behavior, with the production of a droplet of waxy fluid discharged from abdominal ostioles that apparently derives from the hemolymph and solidifies on contact with air (Gullan and Kosztarab 1997), as well as encapsulation of parasitoid eggs and larvae (Suma et al. 2012; Bugila et al. 2014b). Mating behavior has also important practical implications for the commercial use of A. vladimiri. In this perspective, laboratory mass-reared parasitoids showed a male mating success higher than $80 \%$ (Romano et al. 2018). Furthermore, male and female parasitoids developed faster and females produced more offspring in older hosts (Güleç et al. 2007).

Both sexes of parasitoids are innately attracted to VMB sex pheromone, which elicits a kairomonal response (Franco et al. 2008, 2011). In fact, $A$. vladimiri has been caught in $P$. 


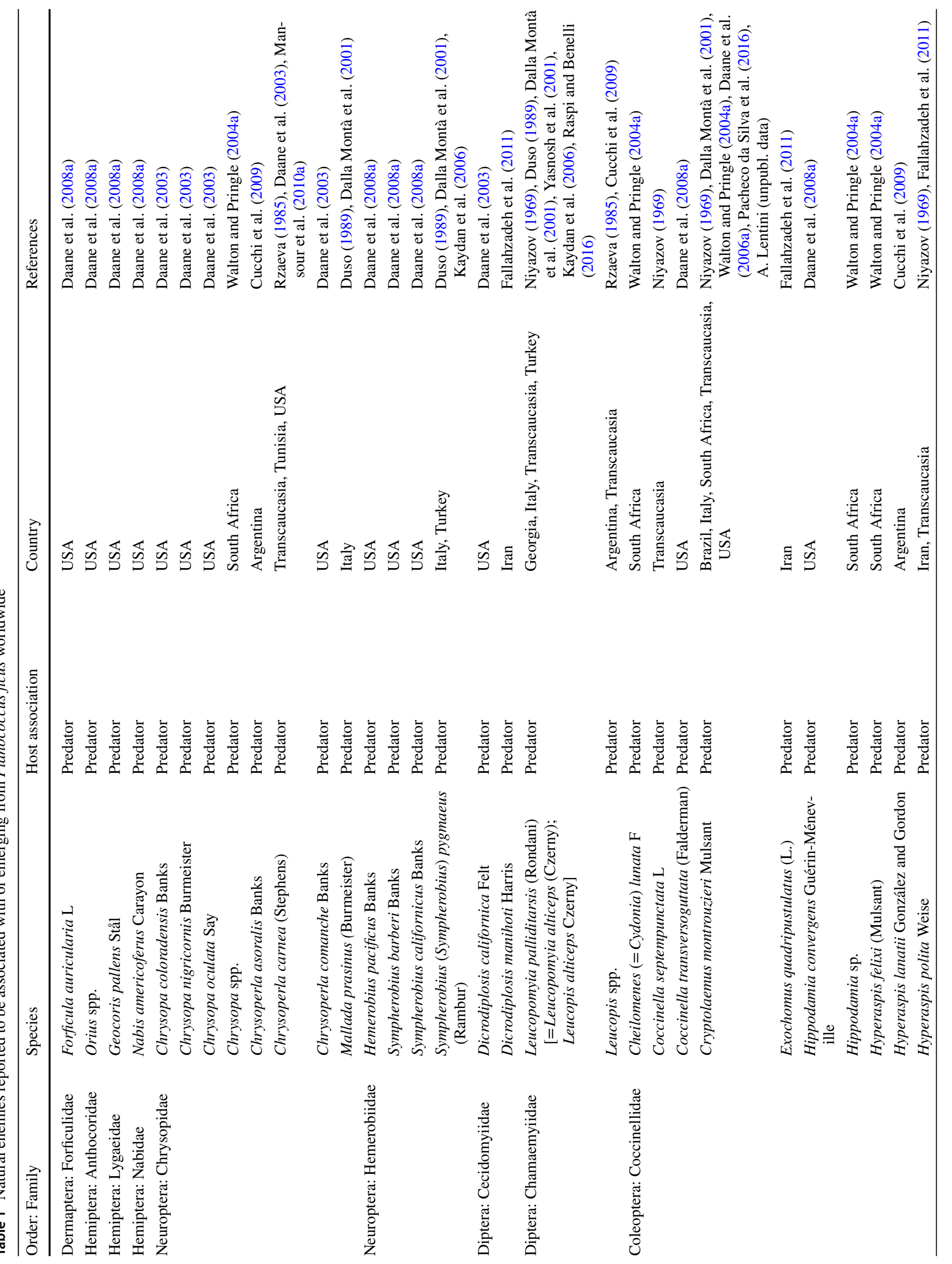




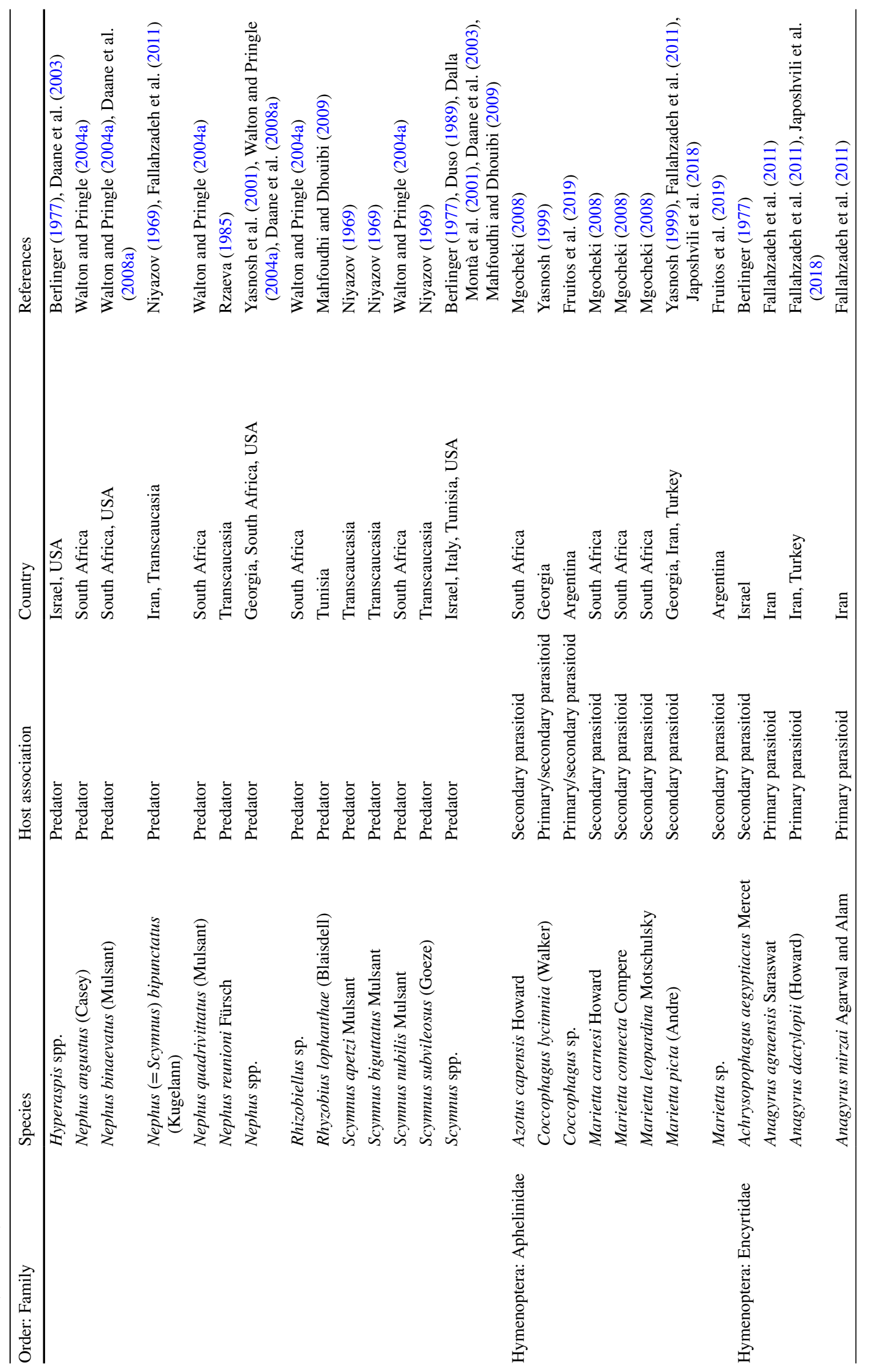




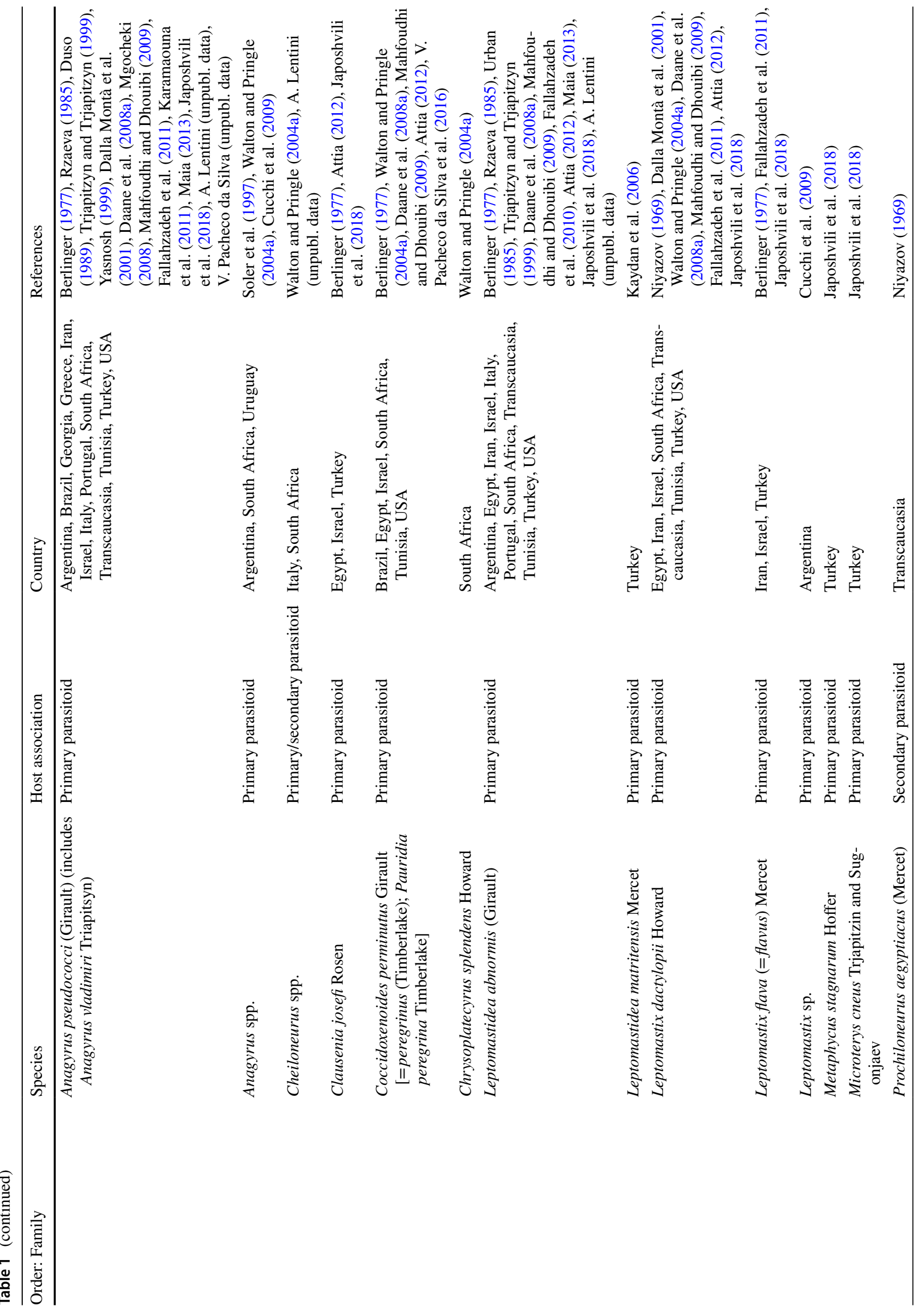




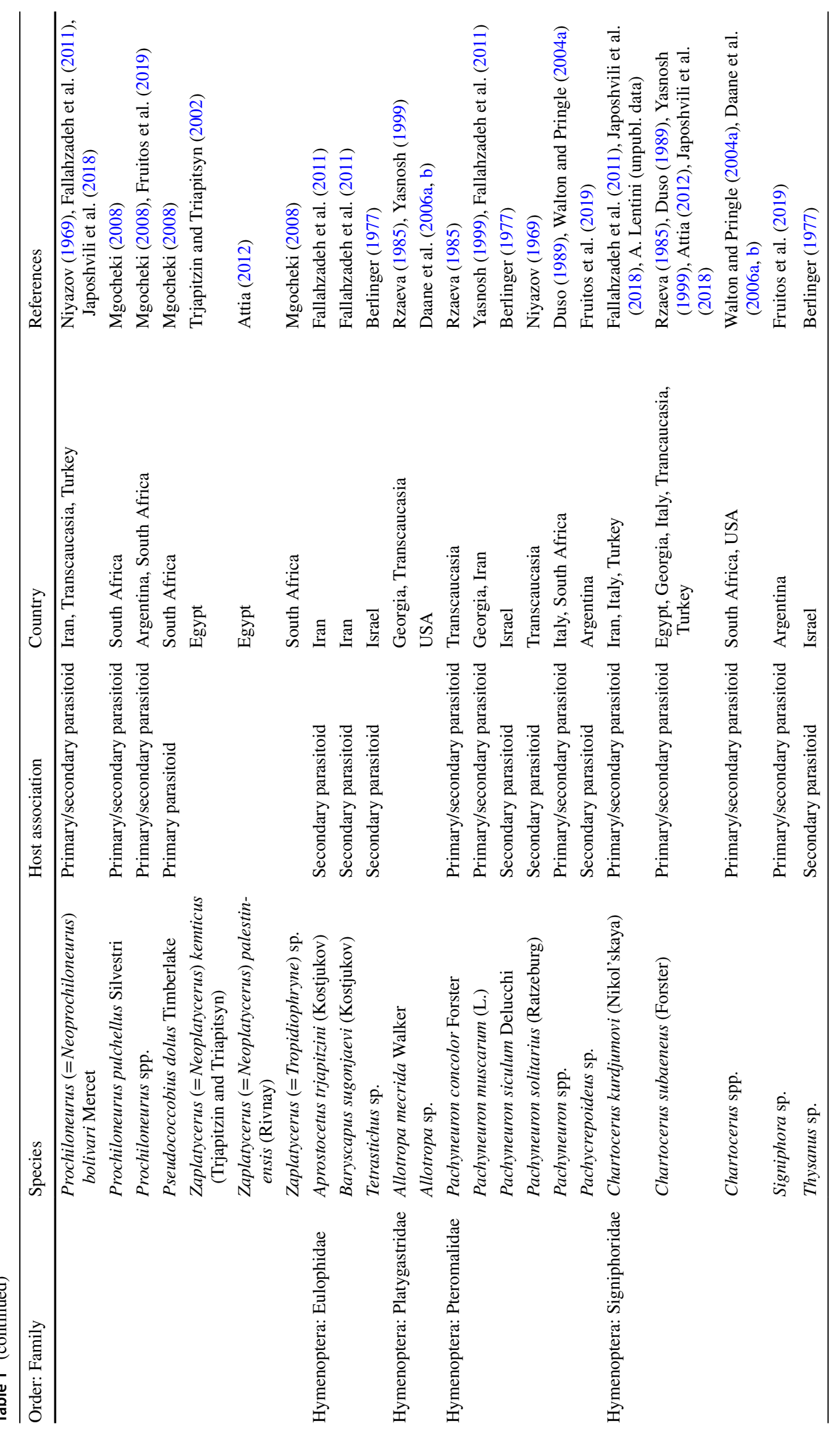


Fig. 4 Major natural enemies of Planococcus ficus: a the encyrtid parasitoid Anagyrus vladimiri performing antennal tapping and $\mathbf{b}$ oviposition on a P. ficus female (note the parasitoid wings in vertical position to avoid the peculiar defensive behavior of $P$. ficus in response to parasitization, i.e., the production of a droplet of waxy fluid discharged from abdominal ostioles), $\mathbf{c}$ adult and d larva of the coccinellid predator Cryptolaemus montrouzieri (photograph credit a-c: R.

Ricciardi, d: V. C. Pacheco da Silva)
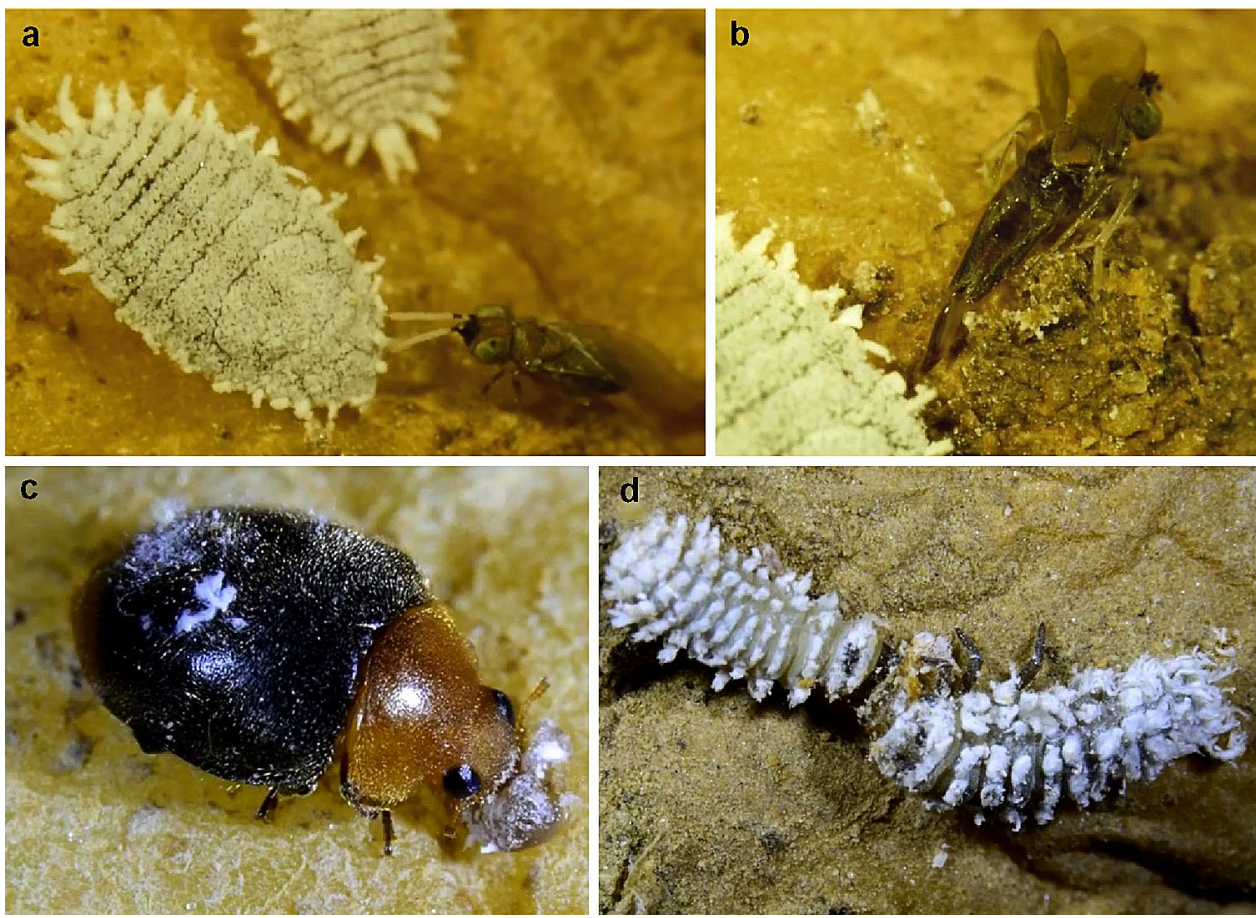

ficus pheromone-baited traps (Millar et al. 2002; Mansour et al. 2010b), indicating that pheromone serves as a chemical cue in host location. Host recognition occurs through antennal examination and is related to the waxy covering of mealybugs. Another factor enhancing the host searching activity of $A$. pseudococci s.l. (likely A. vladimiri) is the presence of the mealybug honeydew. Indeed, parasitoids walked slower and stopped more frequently on tomato leaves contaminated with $P$. citri honeydew compared to clean ones (Khandakar and Jahan 1993).

From an applied point of view, few studies assessed the efficacy of inoculative or inundative releases of A. pseudococci s.l. in reducing the population density of VMB in vineyards, and their results were inconclusive. Daane et al. (2006a) reported that releases of mass-reared A. pseudococci in California vineyards contributed to mealybug biological control programs, as VMB population density and cluster damage were significantly lower in Anagyrus-released plots than in control plots. However, the same authors cannot conclude that three inundative releases of 24,700 parasitoids per hectare were solely responsible of the VMB reduction, since the mealybug density decreased before the first $A$. pseudococci $i$ s.l. release and the season-long parasitism rate was not significantly different between treatments. Further studies carried out in California showed that four inundative releases of 37,000 A. pseudococci s.l. per hectare associated with a single application of imidacloprid reduced the mealybug density compared with the insecticide application alone, although the impact of parasitoid releases was marginal (Tollerup 2007). Biological control programs also investigated early spring releases of 10,000-50,000 A. pseudococci s.l. per hectare to control P. citri in citrus orchard (Mendel et al. 1999). Augmentative releases increased significantly the parasitoid population density but did not reduce the mealybug infestation nor the fruit damage. On the other hand, inoculative release of $A$. vladimiri carried out in Tuscany (central Italy) was effective in managing VMB populations in heavily infested vineyards. Releases of $A$. vladimiri in May (1,000 insects/ha) and C. montrouzieri in June and/or July (500 insects/ha) were extremely promising, leading to a significant reduction of the mealybug population (Lucchi and Benelli 2018). The effectiveness of natural enemies was assessed by checking A. vladimiri parasitism rates in mid-July and at harvest and estimating the abundance of $C$. montrouzieri larvae and adults in VMB colonies. Currently, these biological control agents are employed to manage $P$. ficus in coastal Tuscany (Livorno province, Italy) in more than 800 ha. The recommended release rate of A. vladimiri ranges widely from 500 to 5,000 individuals/ha depending on pest pressure and biocontrol company. Releases start from the migration of crawlers to the canopy and the number of releases vary from 1-2 to 4-8 (Associates Insectary, Bioplanet, Koppert Italy, pers. comm.). Currently, A. pseudococci s.l. for mealybug control in vineyards is released in California, South Africa and Europe, where it is distributed over about 5000 ha mainly in Italy and Spain.

Overall, the variable outcomes resulting from inoculative and inundative releases of $A$. pseudococci s.l. can be due to several constraining factors that can hamper the efficacy of this encyrtid, such as the detrimental side effects 
of pesticides on released parasitoids and the disturbance of the parasitoid action by mealybug-tending ants. Further aspects that affect the parasitoid population increase are (1) the release rate of parasitoids in relation with the pest density; (2) P. ficus in autumn-winter months remains mostly concealed under the bark, being therefore protected from foraging parasitoids; (3) A. pseudococci s.l. is characterized by low densities early in the season, as parasitoid adults mostly emerge in late spring; and (4) timely release of parasitoids when suitable host stages are present, as they prefer larger VMB specimens, particularly for female offspring development (Daane et al. 2006a). In this regard, the limited supplies for short periods during peak seasonal demand, i.e., in spring, may also prevent the release of beneficials in the optimal time (Associates Insectary, pers. comm.).

\section{Leptomastix dactylopii Howard (Hymenoptera: Encyrtidae)}

Leptomastix dactylopii Howard (Hymenoptera: Encyrtidae) is a polyphagous mealybug parasitoid, which has been introduced in the Mediterranean basin, USA, Australia, India and Pakistan in biological control programs mainly against $P$. citri. Lately, L. dactylopii emerging from P. ficus in vineyards has been reported from Tunisia, Egypt, South Africa, Turkey and Iran (Walton and Pringle 2004b; Mahfoudhi and Dhouibi 2009; Fallahzadeh et al. 2011; Attia 2012; Japoshvili et al. 2018). This parasitoid was also released in the 1990s in classical biological control programs in California vineyards together with other mealybug parasitoids, with no significant mealybug control (Daane et al. 2008a). The main factor affecting the inadequate effectiveness of $L$. dactylopii is most likely the climate, as the parasitoid is unable to overwinter in the Mediterranean climatic conditions of southern Europe (Franco et al. 2004). The estimated lower temperature threshold of $L$. dactylopii is higher than that of L. abnormis and A. pseudococci (Tingle and Copland 1988), and no oviposition occurs at temperatures lower than $18{ }^{\circ} \mathrm{C}$ (Zinna 1960).

The effectiveness of $L$. dactylopii against VMB could be manipulated in mass-rearing facilities. In fact, laboratory experiments demonstrated that $L$. dactylopii can successfully complete its development on $\mathrm{VMB}$, showing a reproductive fitness comparable with that observed on $P$. citri, and a very low effective encapsulation rate (5\%) (Marras et al. 2016). Furthermore, the host preference for VMB can be increased by rearing the parasitoid on its target pest. The potential innate preference of the parasitoid for $P$. ficus over P. citri is probably due to the common native area of origin (KolMaimon et al. 2015). Further field observations highlighted higher captures of mass-reared $L$. dactylopii in transparent sticky traps baited with $P$. ficus pheromone than P. citri pheromone. Furthermore, P. ficus third instars and young females field-exposed in "potato traps" (see description in
Franco et al. 2011) were parasitized by L. dactylopii more than $P$. citri individuals, indicating that this parasitoid is attracted by VMB pheromone and is able to parasitize this species in the field also in the presence of $P$. citri (P.M. Marras, AGRIS Sardegna, pers. comm.). Despite the promising laboratory results, $L$. dactylopii is not presently being used in vineyard biological control programs, probably because of the costs related with yearly inoculative releases and the lack of effectiveness in field experiments.

\section{Coccidoxenoides perminutus Girault (Hymenoptera: Encyrtidae)}

Coccidoxenoides perminutus $(=$ Coccidoxenoides peregrinus) is a parasitic wasp native to Australia, nowadays widely distributed in northern and southern Africa, USA, the Middle East, India and Brazil (Daane et al. 2008a; Mahfoudhi and Dhouibi 2009; Fallahzadeh and Japoshvili 2010; Attia 2012; Amala et al. 2013; Pacheco da Silva et al. 2016), and introduced in Europe for classical biological control programs (Italy, UK) (Noyes 2003). Laboratory trials pointed out lower developmental thresholds of $C$. perminutus than P. ficus (Walton and Pringle 2005; Varikou et al. 2010; Sime and Daane 2014), indicating a higher adaptability to low temperatures of the parasitoid which is a suitable biocontrol agent against VMB in temperate grape-growing regions (Walton and Pringle 2005). The same studies indicated the optimal temperature for population growth to be $25^{\circ} \mathrm{C}$, whereas the maximum developmental temperature could not be determined and was estimated as higher than $30-31{ }^{\circ} \mathrm{C}$ (Walton and Pringle 2005; Sime and Daane 2014).

Under laboratory conditions, this species exhibited some advantages as a biocontrol agent over $A$. vladimiri. In fact, $100 \%$ of the C. perminutus offspring is female in view of the thelytokous reproduction, compared to $33.8 \%$ of $A$. vladimiri, and $C$. perminutus females produced more offspring than A. vladimiri (Sime and Daane 2014). Coccidoxenoides perminutus exhibited a lower host-handling time than A. vladimiri, so that its reproductive success was not affected by mealybug-tending ants.

Coccidoxenoides perminutus under optimal climatic conditions can achieve high parasitism rates to the extent that it can infest facilities producing biocontrol agents and hamper the mass rearing of mealybugs. However, such high reproductive performance was not always reflected in the field, in which unsatisfactory results were observed in some cases (Davies et al. 2004). The poor parasitoid response in the field could be due to a limited tolerance to concomitant conditions of low relative humidity and high temperature. In addition, female parasitoids do not discriminate among mealybug stages (crawlers, second- and third-instar nymphs and young and mature females) for oviposition, although the highest parasitoid offspring ( $82 \%$ ) is produced from 
second-instar nymphs. This non-selective oviposition behavior is a shortcoming in a mixed population of mealybugs, as females oviposit indifferently on all host stages, thereby reducing the reproductive efficiency (Sime and Daane 2014). A field trial investigating $C$. perminutus mass releases as a potential alternative to conventional organophosphate insecticide control against $P$. ficus in South Africa highlighted that 5-6 augmentative releases of 20,000 parasitoids per hectare increased the parasitism rate by $8-13 \%$ and reduced the crop loss by $0.5-2 \%$ compared to chemical control (Walton and Pringle 2003).

More parasitoid and hyperparasitoid species have been reported emerging from $\mathrm{VMB}$, even though their activity alone is insufficient to effectively contain its populations below economic damage levels (Table 1).

\section{Predators}

\section{Lady beetles (Coleoptera: Coccinellidae)}

The most important predator of mealybugs in the vineyards is the generalist mealybug destroyer, C. montrouzieri, native to Australasian region and introduced worldwide (Fig. 4b). This beetle has been used in classical biological control programs against $P$. ficus, $M$. hirsutus, $P$. calceolariae, $P$. longispinus and Phenacoccus aceris Signoret (Hemiptera: Pseudococcidae) in India, USA, Chile and Europe (Daane et al. 2012).

Females can lay up to 400 eggs into or near mealybug ovisacs. Larvae are covered with waxy filaments along the body margins and, to some extent, resemble their mealybug preys. Fourth-instar larvae are most effective in the predatory activity, being able to consume up to 12 mealybugs/day (Muştu et al. 2008). However, both larvae and adults actively prey on mealybugs, and a single individual can eat up to 1000 eggs or 500 juvenile mealybug instars in its lifetime (Daane et al. 2012). Larvae can detect preys only by physical contact, whereas adults perceive mealybugs by visual and chemical stimuli (Heidari and Copland 1992). Among the latter, chemical cues through contact with mealybug waxy filaments trigger $C$. montrouzieri oviposition behavior (Merlin et al. 1996). Furthermore, females respond in a speciesspecific way to mealybug pheromone stimuli (Urbina et al. 2018), showing a more active searching behavior when exposed to $P$. calceolariae pheromone over $P$. viburni pheromone. This could be due to co-evolution of $C$. montrouzieri and $P$. calceolariae in the same native area, Australasia, whereas $P$. viburni is native to South America.

Being native to tropical Australasian region, the mealybug destroyer development and reproduction are severely affected by temperature, to the extent that, in some temperate regions, it cannot overwinter in sufficient numbers to suppress effectively mealybug infestations (Muştu et al. 2008).
The reported optimal temperatures for survival and reproduction ranged from 28 to $30^{\circ} \mathrm{C}$ (Hussey and Scopes 1985; Saljodi et al. 2014), whereas the optimum temperature based on values of life table parameters was $26{ }^{\circ} \mathrm{C}$ (Saeedi et al. 2015), indicating this temperature as the most suitable for mass rearing of $C$. montrouzieri. This lady beetle requires higher developmental temperature than parasitoids commonly used in vineyards. Therefore, spaced releases are suggested in the growing season in combined biological control programs: earlier releases of parasitoids and later releases of predators. Indeed, this strategy was recently applied in a high-value wine grape area in Tuscany (Italy) by releasing A. vladimiri and C. montrouzieri at a rate of 1,000 parasitoids/ha in May and 500 predators/ha in late June-July, respectively (Lucchi and Benelli 2018). This strategy met with the approval of grape growers to the extent that biological control was extended from 20 to 800 ha in two years in an area-wide biological control program. In California, C. montrouzieri is distributed in 1-2 releases starting from early spring at rates of $1200-5000$ adults/ha (Associates Insectary 2020).

Nephus kreissli Fürsch and Uygun (Coleoptera: Coccinellidae) is a small-sized predatory beetle naturally occurring in vineyards in the Middle East and can therefore represent a potential biocontrol agent of $P$. ficus in Mediterranean vineyards (Muştu and Kilinçer 2013). At constant laboratory temperature of $28{ }^{\circ} \mathrm{C}$, the egg-to-adult development was completed in 31 days, whereas the adult longevity was about 66 days in both males and females. Over their lifespan, females laid on average 122 eggs. Preferred preys of first- and second-instar coccinellid larvae were mealybug eggs, whereas third- and fourth-instar larvae preyed preferentially on second- and third-instar nymphs and adult females of $P$. ficus. The consumption of eggs increased with the development of $N$. kreissli immatures, and fourth-instar larvae showed the highest predation rate (Muştu and Kilinçer 2013).

Other lady beetle species have been recorded preying on grape mealybugs in grape-growing areas worldwide (California, Mediterranean basin, South Africa, the Middle East, Argentina) (Dalla Montà et al. 2001; Walton and Pringle 2004a; Daane et al. 2008a; Cucchi et al. 2009; Mahfoudhi and Dhouibi 2009; Fallahzadeh et al. 2011) (Table 1). Species of the sub-family Scymninae (Hyperaspis, Nephus and Scymnus spp.) are common resident species in vineyards and may be of high importance in controlling mealybugs at low pest density as their activity is less dependent on high population densities than C. montrouzieri (Daane et al. 2008a). Migratory lady beetles, mostly of the sub-family Coccinellinae (Coccinella and Hippodamia spp.), are in turn attracted by highly infested vineyards. However, the impact of lady beetles, except $C$. montrouzieri and $N$. kreissli, on mealybug species associated with grapevine has not been assessed. 


\section{Other mealybug predator species}

Several generalist predators are established in vineyards and have been observed feeding on mealybugs. Larvae of several lacewing species prey on smaller instars, whereas effective predation is more difficult on eggs, because of the protective waxy filaments of ovisacs, and on larger instars, which show defensive responses such as abdominal flipping or reflex bleeding. Chrysopid species associated with grape mealybugs include Chrysopa oculata Say, C. nigricornis Burmeister, C. coloradensis Banks and Chrysoperla comanche Banks in California (Daane et al. 2003, 2008a), Chrysoperla asoralis Banks in Argentina (Cucchi et al. 2009), Chrysoperla carnea (Stephens) in California and Tunisia (Daane et al. 2008a; Mansour et al. 2010a) and Mallada prasinus (Burmeister) in Italy (Dalla Montà et al. 2001) (Table 1). In spring, brown lacewings predators belonging to Sympherobius and Hemerobius genera may provide complimentary mealybug control being active at low temperatures. Currently, C. carnea is released in table-grape vineyards in California as a generalist predator of mealybugs as well as of mites and leafhoppers.

Among Diptera, larvae of the cecidomyiid and chamaemyiid flies Dicrodiplosis spp. and Leucopomyia palliditarsis (Rondani) (=Leucopis alticeps Czerny) have been recorded feeding on mealybug eggs and crawlers in vineyards (Daane et al. 2008a; Fallahzadeh et al. 2011). Furthermore, the hemipteran predatory bugs Geocoris pallens Stål, Nabis americoferus Carayon and Orius spp. commonly prey on mealybugs in vineyards, yet their density is usually low (Daane et al. 2008a). Spiders are the most common insect predators in vineyards, representing up to $90 \%$ of total predators (Costello and Daane 1999), and Theridion sp. was observed preying on second-instar nymphs of P. maritimus (Geiger and Daane 2001). The ability of all the above-mentioned predators to effectively reduce mealybug infestations has not been determined, and most likely, they contribute secondarily to mealybug control associated with more specialized parasitoids and predators, i.e., A. pseudococci s.l. and C. montrouzieri.

\section{Entomopathogens}

\section{Nematodes}

Entomopathogenic nematodes show some valuable traits as potential biocontrol agents, including the active searching behavior that allow to find mealybugs in concealed locations and the possible application on both the soil and canopy. On the other hand, nematode infectivity is strictly related to the humidity of the substrate that in some cases hinders the pathogenicity of nematodes. Laboratory screening of two nematode-based commercial products and six South
African indigenous species highlighted as most promising species Steinernema yirgalemense Nguyen, Tesfamariam, Gozel, Gaugler and Adams and Heterorhabditis zealandica Poinar, which caused $65 \%$ and $96 \%$ mortality rates in VMB adult females, respectively, and also showed the ability to move downward in a sandy substrate to infect mealybugs (Le Vieux and Malan 2013). Further field trials indicated a higher pathogenic activity and soil persistence ability of S. yirgalemense (Le Vieux and Malan 2015). In addition, infective juveniles of that species were attracted by organic compounds produced by grapevine roots and mealybug adult females. However, infectivity of S. yirgalemense was deeply affected by temperature and, above all, relative humidity, as mortality rates decreased from 70 to $40 \%$ when $\mathrm{RH}$ decreased from 100 to $60 \%$ (Platt et al. 2018). Therefore, laboratory and glasshouse experiments were carried out with the aim to increase the nematode survival and infectivity in foliar applications by adding adjuvants, such as polysaccharide starch and spreader (Platt et al. 2019). Addition of adjuvants concurred to increase mortality of $P$. ficus females by $S$. yirgalemense to $88 \%$ compared with nematode application with water alone.

\section{Fungi}

Studies on the potential use of entomopathogenic fungi in the control of VMB have increased in recent years in view of the rising demand for sustainable grapevine protection. Isaria farinosa (Holmsk.) applied on leaves infested by $P$. ficus under laboratory conditions caused mortality rates up to $90.6 \%$ at $95 \%$ relative humidity (RH) in first-instar nymphs, whereas the lowest mortality was observed in eggs (68.7\%) (Muştu et al. 2015). Common fungicides used in organic farming, such as sulfur and copper oxychloride, did not affect the entomopathogenic activity of $I$. farinos $a$ on $P$. ficus. Therefore, the main limiting factor mining its practical application in vineyards is the strong relation between effectiveness and relative humidity. The conidial germination of I. farinosa occurred at $\geq 90 \% \mathrm{RH}$ and its insecticidal efficacy strongly declined to $19.6-34.6 \%$, depending on the mealybug developmental stage, at 60\% RH (Muştu et al. 2015).

The entomopathogenicity of Beauveria bassiana (Balsamo), Metarhizium anisopliae (Metschnikoff) Sorokin and Verticillium lecanii (Zimm.) Viégas to VMB adult females was also studied in a dipping bioassay, which showed the highest mortality by B. bassiana ( $98 \%$ after 7 days) (Mohamed 2016). A similar bioassay highlighted a mortality of $P$. ficus females of $77-87 \%$ caused by $B$. bassiana strains and $69 \%$ by Clonostachys rosea f. catenulata (Link: Fries) Schroers, Samuels, Seifert and Gams (Moloinyane et al. 2019). Moreover, a positive association between some entomopathogens and the occurrence of high levels of soil macronutrients was observed, indicating that a rational 
fertilization increases the natural presence of entomopathogenic fungi in vineyards.

Rondot and Reineke (2018) investigated the influence of endophytic activity of a commercial strain of $B$. bassiana on development and survival of VMB. The commercial microbial product was sprayed on potted plants, kept for two weeks at $23-25{ }^{\circ} \mathrm{C}$ and $50-70 \% \mathrm{RH}$ to allow endophytic establishment. Afterward, leaves were excised and infested with first-instar nymphs, which showed a reduced body size and infestation rate due to endophytic fungal propagules. These findings contrast with those of Moloinyane and Nchu (2019), who observed no influence on the development of $P$. ficus adults and nymphs by $B$. bassiana inoculated on potted vines by drenching.

The natural entomopathogenic activity of fungi has been limitedly investigated. In Portugal, dead VMB were found naturally mycosed by 22 fungal species, including a yeast, with Sarocladium kiliense (Grütz) and Purpureocillium lilacinum (Thom) Luangsa-ard, Houbraken, Hywel-Jones and Samson being the most common pathogens (Sharma et al. 2018). However, the overall percent mortality was quite low (13.6\%), indicating a limited natural efficiency of fungi as biocontrol agents.

\section{Bacteria}

Bacterial isolates have been tested recently for mealybug control. Chromobacterium subtsugae (Martin, Gundersen-Rindal, Blackburn and Buyer) and Burkholderia rinojensis Cordova-Kreylos have been recently isolated and showed insecticidal activity to a broad range of sucking and chewing insects, being therefore commercialized as bioinsecticides (Marrone 2019). The former species was ineffective to P. longispinus infesting orchids (Ray and Hoy 2014), whereas it has been reported to be more toxic than neem oil and buprofezin to the VMB (Marrone 2011). Both C. subtsugae and $B$. rinojensis caused moderate and high mortality levels, respectively, to the Madeira mealybug, Phenacoccus madeirensis Green (Hemiptera: Pseudococcidae) on cotton (Shannag and Capinera 2018). Both commercial products are included in the list of bioinsecticides as potential alternatives to chlorpyrifos in vineyards in California (Ag Innovations 2020).

Bacillus amyloliquefaciens Fukumoto, Paenibacillus polymyxa (Prazmowski) Ash, Priest and Collins and Providencia rettgeri (Hadley, Elkins and Caldwell) caused high mortality (82.6-90.4\%, depending on the bacterial species) in first-instar nymphs of $P$. citri after $72 \mathrm{~h}$ of exposition in laboratory trials (Mohamedova et al. 2017). Regarding the mode of action of bacteria, it has not been fully elucidated and several aspects remain to be clarified. Both B. amyloliquefaciens and P. polymyxa produced cellulolytic enzymes and proteases (serine proteases and metalloenzymes), which have insecticidal properties. Providencia rettgeri produced only acid protease. None of the tested bacteria could degrade the external protective wax, as no lipolytic or chitinolytic enzymes were produced.

\section{Natural products}

Developing novel and effective biopesticides to successfully manage insect pests of agricultural importance is timely and challenging nowadays, to face the quick development of synthetic insecticide resistance in targeted species as well as the close-related detrimental non-target effects on human health and the environment (Pavela and Benelli 2016; Athanassiou et al. 2018; Benelli et al. 2019; Pavela et al. 2020). The use of natural compounds as biopesticides in vineyards against VMB has been investigated in both laboratory and field studies. Orange and lemon essential oils sprayed on leaves infested by VMB adult females and third instars under laboratory conditions were as toxic as paraffin oil, commonly used in organic vineyards against mealybugs (Karamaouna et al. 2013). Further laboratory studies highlighted that citrus essential oils are toxic to VMB when sprayed on the substrate and on nymphs, although direct applications on immatures were more effective (Tacoli et al. 2018). When applied in vineyards under natural conditions, a bioinsecticide based on orange essential oils showed a low persistence but was nonetheless as effective as methidathion and drench-applied imidacloprid in reducing the density of all mealybug instars (eggs, nymphs and adult females) on grape trunks (Mansour et al. 2010a). Tacoli et al. (2018) also observed a reduction in VMB field population density on grape leaves sprayed with a green insecticide based on citrus essential oils, suggesting as optimal spraying time two applications spaced one week apart against crawlers of the second generation at the onset of their migration toward the canopy.

The essential oils pulegone and menthone and the metabolite menthofuran extracted from Minthostachys verticillata (Griseb.) Epling showed a promising fumigant insecticidal activity on adult VMB females (Peschiutta et al. 2017; DezaBorau et al. 2020). However, the potential phytotoxicity and the effectiveness in field applications were not estimated. Other natural products, such as a commercial product based on eugenol, geraniol and limonene, and essential oils extracted from eucalyptus, peppermint, lavender and basil, were either not effective against VMB or showed different levels of phytotoxicity on grape leaves (Karamaouna et al. 2013; Peschiutta et al. 2017). A limitation in the use of organic oils is related to alterations of the berry bloom, so that they are not applied after fruit set in table grapes.

Neem-derived products are bioinsecticides registered in several countries, e.g., USA and Brazil, for use on mealybugs in organic farming (Ag Innovations 2020; M. Botton, unpubl. data), including viticulture, and are reported to 
provide some control on younger instars, which are less protected by waxy covering (Flint 2016). Neem oil is toxic by contact action; applications should therefore target exposed mealybugs and repeated at short-time intervals because of its little persistence (Kreiter 2018). Neem oil applications effectively reduced the density of other mealybug species, although no specific research studies have been carried out on the effectiveness of neem products in controlling VMB.

An insecticidal soap of potassium fatty acids tested in laboratory bioassays caused in nymphs a mortality rate $(69 \%)$ significantly higher than paraffinic oil $(42 \%)$ and pyrethrin, sulfur and spinosad ( $<20 \%$ mortality) (Taskin et al. 2014). However, a field trial in which the insecticidal soap was applied four times against the second and third $P$. ficus generations did not reduce significantly the pest density compared to untreated control (Tacoli et al. 2018).

In field and laboratory trials, applications of an inert particle film (kaolin) had no effect on mealybug mortality but showed a non-significant tendency to reduce the bunch infestation (Tacoli et al. 2018). Therefore, kaolin application for other purpose, such as for increasing the grapevine water use efficiency or for controlling leafhoppers and the spotted wing drosophila, Drosophila suzukii Matsumura (Diptera: Drosophilidae) (Brillante et al. 2016; Tacoli et al. 2017; Linder et al. 2020), may complimentarily hinder the migration of mealybugs to bunches.

Diatomaceous earth is widely used in management programs of several pests, including stored-grain and soft-bodied insects. Its insecticidal effect is mainly due to physical abrasion of the cuticle and adsorption of cuticular lipids, causing exterior mechanical damage, which results in death by dehydration. Diatomaceous earth used as a coformulant acted synergistically with the active substance pulegone increasing the mortality of VMB in laboratory trials (DezaBorau et al. 2020). Diatomaceous earth formulations have been developed for use in organic viticulture on VMB in dry or aqueous solution applications (Todorov 2018). However, its impact on damaging densities of VMB in field conditions is yet unknown.

\section{Pheromone-based management}

Control tactics based on the exploitation of sex pheromones rely on disruption of male-female sexual communication and alteration of the mating behavior of insects to reduce pest population density and, consequently, crop damage. Sex pheromones are being increasingly used in sustainable pest management programs in view of their interesting features, including high species specificity, nontoxicity and safety for public health and the environment (Lucchi and Benelli 2018). Pheromone-based control tactics represent new ecofriendly opportunities to manage mealybug pests, as recently showed for P. citri, P. calceolariae and VMB (Franco et al. 2003; Ricciardi et al. 2019).

The potential application of mating disruption for controlling VMB infestations was firstly investigated in California by testing rope and membrane dispensers and a microencapsulated flowable formulation of the synthetic sex pheromone (Daane et al. 2020). Results were promising as mating disruption consistently altered male orientation and often reduced the pest density and/or the crop damage, leading to the development of commercial mating disruption products.

The sprayable microencapsulated formulation was effective in reducing the pest density, the percentage of ovipositing females, female fecundity and grape damage (Walton et al. 2006). On the other hand, the activity of the parasitoid A. pseudococci was not altered by mating disruption. However, microencapsulated formulation was effective for 3-5 weeks and required up to four applications in order to ensure a season-long effectiveness (Walton et al. 2006). This formulation has been registered in the USA in 2015 as CheckMate ${ }^{\circledR}$ VMB-F and evaluated in table-grape vineyards in 2016 and 2017 at a rate of $12.5 \mathrm{~g}$ a.i./ha, suppressing male captures in monitoring pheromone traps by about $90 \%$ for 30-45 days (Haviland 2017). Applications of the microencapsulated formulation should be therefore repeated 2-5 times from late May to early October to ensure a continuous disruption of male orientation. The number of applications depends on the pest pressure and harvest period, which usually occurs in September-October for wine grapes and in July-October for table grapes. The main advantage of the flowable formulation resides in the application with conventional sprayers in combination with other control products, except emulsifiable concentrate (EC) products or organosilicone surfactants. On the other hand, this formulation is not registered for use in organic agriculture due to the enclosure of pheromone in polymer capsules in the microencapsulation process. However, some accredited organic-certifying agencies have granted temporary exemptions for its use in California in table-grape vineyards in some specific situations (KCDA 2020).

The membrane dispenser Checkmate ${ }^{\circledR}$ VMB-XL was the first product to be registered for mating disruption control of P. ficus in 2010 in California. Those devices were developed and tested independently in the early 2010s in table and wine grape vineyards in Argentina, Italy, Israel and Tunisia (Miano et al. 2011; Cocco et al. 2014; Sharon et al. 2016; Mansour et al. 2017b). Results were overall consistent, showing the disruption of VMB male orientation and the reduction of mealybug population density. Langone et al. (2014) tested different pheromone loads per dispensers (100-300 mg), dispenser densities (312.5-625/ha) and amounts of pheromone released (62.5-94 g/ha), determining the optimal density at 438 dispensers/ha with a pheromone load of $62.5 \mathrm{~g}$ of active ingredient/ha. Sharon et al. (2016) 
reported a reduction of infested vines in highly infested vineyards by applying mating disruption as a stand-alone control tactic in two consecutive years. VMB control by mating disruption can be effective in small plots (0.5-2.5 ha), differently from mating disruption control of lepidopteran pests, e.g., the European grapevine moth, Lobesia botrana (Denis and Schiffermüller) (Lepidoptera: Tortricidae), which benefits from area-wide management programs (Cooper et al. 2014; Ioriatti and Lucchi 2016). Pheromone rope dispensers (Isonet ${ }^{\circledR} \mathrm{PF}$ ) for VMB mating disruption have been also developed and tested, indicating an increasing interest by manufacturers for this control tactic.

The field lifetime of pheromone dispensers ensured a season-long protection of vineyards, ranging from 120 to 150 days in membrane dispensers (Cocco et al. 2014; Mansour et al. 2017b), while rope dispensers exhibited a longer disrupting efficacy of approximately 200 days (Cocco et al. 2018b). The effectiveness of VMB pheromone-based control resides in delaying and reducing the number of matings to the extent that consecutive applications of mating disruption cause a reduction in the pest population density over years (Cocco et al. 2018b). In particular, a delay in female mating $>7$ days reduced significantly the intrinsic and finite rates of increase and increased the mean generation time and the population doubling time, overall reducing the population growth potential of VMB (Lentini et al. 2018). Use of mating disruption as a stand-alone control method in highly infested vineyards ( $>10$ mealybugs/plant) reduced the proportion of mated females but could not significantly reduce the VMB population density (A. Lentini, unpubl. data). Therefore, further studies are required to determine the critical mealybug density beyond which mating disruption should be complemented with additional practices for successful VMB control.

Lucchi et al. (2019) evaluated recently the efficacy of Isonet ${ }^{\circledR} \mathrm{PF}$ testing 300, 400 and 500 dispensers/ha at four study sites located in northern and southern Italy. Results collected over two years showed that mating disruption successfully reduced the percentage of $P$. ficus-infested bunches and the number of mealybugs per bunch, if compared to untreated controls, and no differences in the incidence of infested bunches among the three tested rates of Isonet ${ }^{\circledR} \mathrm{PF}$ were observed. Collectively, the results obtained with membrane and rope dispensers indicate that the optimal density to effectively manage $P$. ficus populations is density dependent and influenced by the infestation degree of the pest in vineyards. Studies are currently ongoing to develop a dualpurpose dispenser, Isonet ${ }^{\circledR} \mathrm{LPF}$, for the concurrent control of P. ficus and L. botrana (Baba et al. 2019).

Aerosol spray cans (Puffer ${ }^{\circledR}$ VMB) were also developed and provided effective control of VMB when deployed at the density of 5 cans/ha and complemented with applications of chlorpyrifos and spirotetramat in winter and post-harvest, respectively (Langone et al. 2014). Despite the promising results, this device was not further developed and did not reach the commercial stage.

Currently, mating disruption of VMB is applied worldwide on approximately 130,000 ha in Italy, Spain, Greece, South Africa, Argentina, Uruguay and California, which is the most important grape-growing area applying this tactic on more than 100,000 ha (CBC Europe, Suterra, pers. comm). Overall, the adoption of mating disruption is growing worldwide; this tactic was in fact used in the early $2010 \mathrm{~s}$ on about 10-12,000 ha in California and less than 1000 ha in Europe. This increase has mostly occurred since 2015 in California after the registration of CheckMate ${ }^{\circledR}$ VMB-F, which is mostly used in non-organic vineyards in association with insecticides. For example, in Kern County, which has a grape area of 27,300 ha (about $10 \%$ of total area of California) with table and wine grape in organic and conventional production, applications of the microencapsulated formulation increased from about 50 to 7000 ha from 2016 to 2020, whereas the use of dispensers decreased from 1100 to 320 ha in the same period (KCDA 2020). Currently, mating disruption control in organic vineyards in Kern County is carried out over 800 ha using the flowable formulation, because of the exemptions granted by certifying organizations, and 220 ha with membrane dispensers.

\section{Key factors affecting the management of Planococcus ficus in organic viticulture}

\section{Interaction of organic-approved control tactics}

Sustainable control tactics applied for pest and disease control in organic viticulture may interact synergistically or antagonistically, thereby affecting the overall control of the VMB. For example, the most important VMB parasitoid, A. vladimiri, shows a kairomonal response to the host sex pheromone, using the chemical cue for host location (Franco et al. 2008). In this framework, mating disruption may alter the foraging behavior of the parasitoid and reduce its effectiveness. The interaction between biocontrol agents and pheromone-mediated control of $P$. ficus has been investigated by Shapira et al. (2018b). These authors observed that the diversity and abundance of natural enemies of $\mathrm{VMB}$ in Israeli vineyards were not affected by mating disruption against $P$. ficus and L. botrana, except for A. vladimiri. Indeed, female parasitoids were mainly captured in control plots, whereas male captures were low and not influenced by mating disruption. However, parasitized VMB were detected only in mating disruption plots, showing that this encyrtid species forages actively in mating disruption areas. These results are in accordance with early studies on the effectiveness of mating disruption on P. ficus (Walton et al. 2006; 
Cocco et al. 2014), in which parasitism rates by $A$. vladimiri were higher in vineyards protected with mating disruption. Higher parasitism rates can be linked to parasitoid females spending more time searching for mealybugs in vineyards protected with mating disruption (Mansour et al. 2010b; Daane et al. 2012).

Bioinsecticides may not be selective to beneficial arthropods, causing both acute toxicity and sublethal effects on behavioral and reproductive traits (Biondi et al. 2012; Soares et al. 2019, 2020). A commercial bioinsecticide based on orange oil was rated as harmless to A. vladimiri adults, following the insecticide classification by the International Organization for Biological and Integrated Control (IOBCWPRS) (Sterk et al. 1999), as it showed no contact toxicity and no effect on parasitoid progeny (Mansour et al. 2011a). Similarly, potassium fatty acids and paraffin oil were selective (mortality $<20 \%$ ) to A. vladimiri, whereas pyrethrin and sulfur caused $76 \%$ mortality (Taskin et al. 2014). Natural products also differed in their selectivity to C. montrouzieri, as potassium fatty acids and pyrethrin caused adult mortality rates of 90 and $75 \%$, respectively, whereas paraffin oil and sulfur were harmless (Taskin et al. 2014).

\section{Intraguild interactions among natural enemies of Planococcus ficus}

Intraguild interactions among natural and released biocontrol agents of $P$. ficus should be considered in the perspective of effective biological control programs. Muştu and Kilinçer (2014) studied the predation by $N$. kreissli on mealybugs harboring A. pseudococci s.l. and L. dactylopii larvae. Fourth instars and adults of $N$. kreissli predated 2- and 4-day-old mealybugs parasitized by the two parasitoids, while older ones were not preyed on, probably because of the onset of mummification. Interestingly, both adults and larvae preferentially predated $A$. pseudococci-parasitized mealybugs over unparasitized ones. To avoid a reduction of the parasitoid efficiency, the predator release should follow by at least 8 days the parasitoid release. Notwithstanding the drawbacks due to interspecific competition, the combined use of the three natural enemies would be more effective than single releases of each beneficial insect (Muştu and Kilinçer 2014). Muştu et al. (2008) also studied the feeding behavior of $C$. montrouzieri on P. ficus and P. citri parasitized by A. pseudococci s.l., showing that beetle larvae and adults were unable to discriminate between unparasitized and newly parasitized mealybugs. The highest consumption values for all tested stages of $C$. montrouzieri occurred in fact with 2and 4-day parasitized mealybugs, whereas mealybugs parasitized by more than 6 days were discarded because of the appearance of mealybug mummies. Similarly to N. kreissli, predator-parasitoid intraguild interaction could negatively affect biological control programs employing both species. It was therefore suggested to space $A$. pseudococci s.l. and $C$. montrouzieri releases by at least 6 days (Muştu et al. 2008).

Interspecific competition may also occur between the major VMB parasitoid, A. pseudococci s.l. and L. dactylopii, when they are used simultaneously to control $P$. ficus. In this context, A. pseudococci s.l. may be more affected than $L$. dactylopii; in fact, when the latter had parasitism priority for $72 \mathrm{~h}$, its emergence rate was approximately $95 \%$, while parasitism priority by A. pseudococci s.l. led to an emergence rate of 77.5\% (Muştu and Kilinçer 2015). Although inoculative releases of $L$. dactylopii in vineyards could affect the activity of A. pseudococci s.l., Muştu and Kilinçer (2015) believe that parasitoid combination might be more successful than single use of natural enemies.

\section{Relationship of Planococcus ficus with ants (Hymenoptera: Formicidae)}

Planococcus ficus, as well as other honeydew-producing insects, is often tended by ants in a mutualistic relationship called trophobiosis. This relationship is based on the consumption of the honeydew secreted by the ants, which in exchange protect the honeydew producers from their natural enemies (Delabie 2001; Daane et al. 2007; Mansour et al. 2012; Feng et al. 2015). Ants may also improve the habitat quality and fitness of mealybugs by removing the excess of honeydew, which can trap crawlers and prevent their spread in the canopy. In fact, the Argentine ant, Linepithema humile Mayr, promoted the population increase of the obscure mealybug by increasing the survival of crawlers independently by the presence of parasitoids (Daane et al. 2007).

Besides, ants can act in the dispersion of mealybugs and benefit the growth of their populations (Way 1963; Daane et al. 2007; Mgocheki and Addison 2010; Zhou et al. 2012), being considered as an indirect vineyard pest (Walton et al. 2012). Several ant genera have been associated with mealybugs and other scale insects commonly found in vineyards (Coccidae, Margarodidae and Monophlebidae), especially those from the subfamilies Myrmicinae (Crematogaster, Pheidole and Solenopsis), Dolichoderinae (Linepithema and Tapinoma) and Formicinae (Camponotus, Formica, Lasius and Plagiolepis) (Franco et al. 2009; Beltrà et al. 2017).

The ant species associated with mealybugs in vineyards vary according to the grape-producing country (Table 2).

\section{Influence of ants on mealybug biological control}

As mentioned above, the natural enemies' activity is disrupted by ants that protect and provide refuge for mealybugs. In Californian vineyards, it was observed an increased parasitism level and reduced mealybug densities in antexcluded treatments (Daane et al. 2003, 2007). In laboratory conditions, Crematogaster peringueyi Emery and $L$. 
Table 2 Ant species associated with mealybugs in vineyards worldwide

\begin{tabular}{|c|c|c|}
\hline Ant species & Country & References \\
\hline \multicolumn{3}{|l|}{ Dolichoderinae } \\
\hline Iridomyrmex spp. & Australia & Sharley et al. (2008) \\
\hline Linepithema humile Mayr & Argentina, South Africa, USA & $\begin{array}{l}\text { Addison and Samways (2000), Varela et al. (2006), Daane et al. (2007), } \\
\text { Schulze-Sylvester et al. (2018) }\end{array}$ \\
\hline Linepithema micans (Forel) & Brazil & Nondillo et al. (2017) \\
\hline Tapinoma nigerrimum (Nylander) & Portugal, Tunisia & Mansour et al. (2011b), Zina and Franco (2015), Gonçalves et al. (2017) \\
\hline Tapinoma simrothi (Krausse) & Italy & Serra et al. (2006) \\
\hline \multicolumn{3}{|l|}{ Formicinae } \\
\hline Anoplolepis custodiens (Smith) & South Africa & Addison and Samways (2000) \\
\hline Anoplolepis steingroeveri (Forel) & South Africa & Addison and Samways (2000) \\
\hline Cataglyphis hispanica (Emery) & Portugal & Gonçalves et al. (2017) \\
\hline Cataglyphis iberica (Emery) & Portugal & Gonçalves et al. (2017) \\
\hline Formica aerata Francoeur & USA & Daane et al. (2003) \\
\hline Formica perpilosa Wheeler & USA & Daane et al. (2003) \\
\hline Lasius grandis (Forel) & Spain & Beltrà et al. (2017) \\
\hline Lasius niger (Linnaeus) & Italy & Serra et al. (2006) \\
\hline Messor barbarus (Linnaeus) & Portugal & Zina and Franco (2015), Gonçalves et al. (2017) \\
\hline Messor structor (Latreille) & Italy & Masoni et al. (2017) \\
\hline Plagiolepis pygmaea (Latreille) & Portugal & Zina and Franco (2015) \\
\hline Plagiolepis schmitzii Forel & Spain, Tunisia & Mansour et al. (2011b), Beltrà et al. (2017) \\
\hline Tetramorium caespitum (Linnaeus) & Portugal & Zina and Franco (2015) \\
\hline \multicolumn{3}{|l|}{ Myrmicinae } \\
\hline Aphaenogaster gibbosa (Latreille) & Portugal & Gonçalves et al. (2017) \\
\hline Aphaenogaster iberica Emery & Portugal & Gonçalves et al. (2017) \\
\hline Crematogaster scutellaris (Olivier) & Italy & A. Lentini (unpubl. data) \\
\hline Crematogaster melanogaster Emery & South Africa & Addison and Samways (2000) \\
\hline Crematogaster peringueyi Emery & South Africa & Addison and Samways (2000) \\
\hline Crematogaster schmidti (Mayr) & Tunisia & Mansour et al. (2011b) \\
\hline Pheidole aberrans Santschi & Brazil & Nondillo et al. (2017) \\
\hline Pheidole pallidula (Nylander) & Italy, Spain, Tunisia & Mansour et al. (2011b), Beltrà et al. (2017), Masoni et al. (2017) \\
\hline Pheidole subarmata Mayr & Brazil & Nondillo et al. (2017) \\
\hline Pheidole teneriffana Forel & Tunisia & Mansour et al. (2011b) \\
\hline Pheidole spp. & Australia & Sharley et al. (2008) \\
\hline Solenopsis invicta Buren & Brazil & Nondillo et al. (2017) \\
\hline Solenopsis fugax Latreille & Italy & Masoni et al. (2017) \\
\hline Solenopsis molesta (Say) & USA & Daane et al. (2003) \\
\hline Solenopsis xyloni McCook & USA & Daane et al. (2003) \\
\hline
\end{tabular}

humile increased the mortality of the parasitoids A. vladimiri and $C$. perminutus and led to a decrease in the parasitism level (Mgocheki and Addison 2009). Mansour et al. (2012) observed that the parasitism of A. vladimiri and L. dactylopii is affected by the presence of the ant Tapinoma nigerrimum (Nylander), mainly due to the ant-induced mortality of these encyrtid parasitoids.

The influence of ants on parasitism is species dependent, since the magnitude and effect of attacks change according to the species involved. The Argentine ant reduced foraging time, oviposition attempts and number of $A$. vladimiri offspring. On the other hand, L. humile did not affect the activity of $C$. perminutus (Sime and Daane 2014), probably due to its smaller size and relatively faster parasitism compared to A. vladimiri, leading to a greater efficiency of $C$. perminutus in the presence of ants (Mgocheki and Addison 2009; Sime and Daane 2014). Campos et al. (2006) also noted a greater attack of Lasius niger (L.) in large body size parasitoids.

Predators are also attacked by foraging ants. The mealybug destroyer $C$. montrouzieri larvae, which have the body covered by waxes mimicking their mealybug prey, are 
ignored by L. humile (Daane et al. 2007), but not by T. nigerrimum, which attacks the larvae but it is harmless to adults (Mansour et al. 2012).

\section{Control of mealybug-tending ants}

Control of tending ants is a recommended measure in mealybug management programs, especially within the framework of organic agriculture, and should be carried out before parasitoid release (Franco et al. 2004; Mgocheki and Addison 2009; Addison and Samways 2012; but see Chailleux et al. 2019). Several studies showed an increase in mealybug parasitism rates when the ants were excluded from the system (Daane et al. 2003, 2007; Mansour et al. 2012; Beltrà et al. 2017).

Different tactics are available for ant management in organic vineyards, ranging from barriers to selective toxic baits; however, some tactics may be impractical in commercial vineyards due to the high costs of application. The use of physical exclusion barriers, such as sticky bands stuck around the vine trunk, has been used to prevent the access of ants to vine canopy (Schwartz 1988; Addison and Samways 2012). Chemical barriers, such as bands impregnated with insecticides, may act as well as an ant barrier. Addison (2002) evaluated several chemical stem barriers to control L. humile and Anoplolepis custodiens (Smith) observing that chlorpyrifos-impregnated bands and terbufos slow-release bands were highly effective in ant control. Weed control through mowing or harrowing may also be important to prevent ants from accessing the area above the stem barriers, as ants can use weed stems and leaves to by-pass the barriers (Addison and Samways 2012). Costello and Welch (2014) observed that weed control caused a reduction in the number of ants in the vines but did not affect mealybug infestation. However, barriers have a low viability in ant control, as they capture only foraging ants, not affecting the ants in the nest.

Since mealybug-tending ants primarily forage for sugar, the use of sugary toxic baits distributed in small doses is more advantageous for killing the whole anthill (Cooper et al. 2008; Daane et al. 2008b; Nondillo et al. 2016). In fact, toxicants are diluted from one ant to another, including larvae and queens, through trophallaxis. Thus, baits with a low concentration of toxicant allow the workers to survive long enough to reach the colony, transmit the toxicant and recruit more ants to the bait (Rust et al. 2004). The preferences of mealybug-tending ants for sugar- or protein-based foods may vary depending on the species and the time of year (Nondillo et al. 2014). Therefore, the kind of bait used is essential for effective ant control, as protein feeders are less successfully controlled by sugar toxic baits.

Liquid baits effective for mealybug-tending ants usually contain an attractant, sugar or protein, water and a toxicant, such as boric acid, hydramethylnon, imidacloprid or thiamethoxam (Rust et al. 2004; Tollerup et al. 2004; Daane et al. 2006b; Cooper et al. 2008; Nondillo et al. 2016). A number of containerized bait stations have been developed for deployment of liquid baits in vineyards, and Gourmet Liquid Ant Bait ${ }^{\circledR}$ baited with disodium octaborate tetrahydrate is registered in California for use in organic viticulture. Liquid ant baits are required at high density and need frequent servicing, which is further increased in hot areas where the water of the active substance evaporates and the concentrated bait is not accepted by ants. Gel-like formulations prepared with hydramethylnon and fipronil have also caused mortality of Linepithema species (Silverman and Roulston 2001; Nondillo et al. 2016), although liquid consumption was higher and caused a greater mortality of the colony, indicating a higher effectiveness of liquid over gel baits (Silverman and Roulston 2001). Polyacrylamide waterstoring crystals containing low doses of thiamethoxam and boric acid suppressed the foraging activity of the Argentine ant in a commercial vineyard for 4-5 months (Cooper et al. 2019) and can be deployed with a tractormounted spreader (Cooper et al. 2019). This could reduce remarkably the application time and cost and may represent a suitable deployment method for implementing a cost-effective ant control strategy. However, presently, all the liquid baits, either containerized or in water-storing crystals, are not broadly used commercially because of their prohibitive costs.

Disruption of ant pheromone trails by dispensers impregnated with synthetic pheromone affects the normal orientation of workers, such as walking, recruitment and foraging. Trail disruption can lead to a greater difficulty for ants in finding the food source, leading to a lower use of resources and a reduction of colony size. The use of trail pheromone has been tested for the control of invasive ants, especially for the Argentine ant and the red imported fire ant, Solenopsis invicta Buren (Suckling et al. 2008, 2010; Tanaka et al. 2009). Choe et al. (2014) evaluated the use of trail pheromones in an attract-and-kill approach, in which the addition of pheromone to insecticides (fipronil and bifenthrin) increased their efficiency, leading to a higher ant mortality due to a higher exposure to toxicants. The effect of trail disruption of hemipteran-tending ants was evaluated in vineyards, determining that the dispensers installed near the base of the grapevines were more efficient, reducing the L. humile traffic in the plants by 73-79\% (Westermann et al. 2016). Presently, trail disruption has been tested mainly on L. humile among the ant species inhabiting vineyards and the economical sustainability has yet to be evaluated, so that no commercial products have been implemented by manufacturers. 


\section{Sustainable integrated management of Planococcus ficus}

The integrated pest management in organic viticulture excludes the employment of synthetic insecticides with the purpose of effectively control grapevine pests and minimizes the impact of control measures on the environment and human health. The previous sections described tools and strategies available in organic viticulture to control VMB populations and reduce their further spread and infestations. Some biological control tactics provided promising results but are still in the experimental evaluation phase and have not been widely applied, while others alternate between effective and insufficient control. In general, single control tools applied as a stand-alone treatment may not be completely effective for high VMB infestations. In addition, monitoring of the distribution and level of mealybug density is essential to pinpoint the infestation foci and concentrate control efforts where they are most needed. Therefore, integrated pest control in organic viticulture requires a holistic approach rather than separate applications against specific pests (Vincent et al. 2012). In some large table-grape farms in California, organic control tools in newly-planted fields are applied for as many years as possible, and when VMB cannot be controlled below the economic threshold with organic-certified tactics, plots are converted to conventional control programs. In this way, each year new fields are started with organic viticulture practices and some are rotated out to integrated chemical control (D. Haviland, University of California, pers. comm.).

Rational strategies to avoid the establishment of VMB populations should be implemented since vineyard planting. Even though cultivar and rootstocks showed different levels of susceptibility to VMB development (Naegele et al. 2020), scion and rootstock choice is driven by economic interests rather than phytosanitary reasons. Nevertheless, planting of mealybug-free nursery stock is critical in order to avoid early infestations on young grape cuttings and postpone mealybug establishment in vineyards (Daane et al. 2004c). Practices aimed at reducing the dispersion of mealybugs from vineyard to vineyard also include a thorough sanitation of vineyard equipment, such as tractors, bins, picking pans and especially mechanical harvesters, which operate when pest population is high and have contact with infested clusters made sticky by honeydew that facilitates mealybug spread.

Irrigation and nitrogen fertilization modify the plant vigor and affect the biotic potential of sap-feeding pests (Cocco et al. 2015; Muscas et al. 2017). The combination and level of water and nitrogen provision mainly depend on production and oenological goals. However, water and nitrogen supply should be balanced not to exceed the pursued quantity and quality objectives. The reduction of the plant vigor and summer pruning generally improve the grape quality and reduce the spatial refuge of mealybugs in the canopy. In addition, a less dense canopy improves the penetration of natural compounds approved in organic agriculture, thereby increasing their effectiveness.

Habitat manipulation, such as conservation of natural vegetation around vineyards, enhances the abundance of natural enemies (Thomson and Hoffmann 2009; Shapira et al. 2018a), as well as cover crop strips provide shelter and food sources (pollen, nectar and alternative preys) to natural enemies within vineyards (Irvin and Hoddle 2015; Benelli et al. 2017). However, such ecosystem services have not been quantified in terms of reduction of VMB infestation or damage. Grass ground covers are established in vineyards with high soil fertility to lower the vigor of plants, which are therefore a less suitable feeding substrate for sapsucking pests such as mealybugs and leafhoppers (Muscas et al. 2017; Wilson and Daane 2017; Daane et al. 2018c). Cover crops also have drawbacks, as no-till management promotes ant nesting and therefore the development of VMB populations.

The cultural practices described above aim to prevent the buildup of mealybug populations to damaging density, but they are not effective against high infestations, so that they should be complemented with more effective control tools. Cultural practices directed at improving the grape and wine quality can be helpful also to mitigate mealybug infestations. For instance, bunches are often thinned to increase berry size in table grapes and improve oenological traits of wine grapes. In that case, removal of bunches touching the trunk that are more likely to be infested would reduce crop losses at harvest (Geiger and Daane 2001). In addition, stripping the bark from trunks and cordons reduce spatial refuge of mealybugs that are therefore exposed to higher risks of mortality by natural enemies (Daane et al. 2006a, 2012; Pavlović et al. 2019).

Mating disruption technique associated with insecticides effectively reduced high populations of $P$. ficus compared with insecticide applications alone in both wine and tablegrape vineyards (Cocco et al. 2014, 2018a, b; Mansour et al. 2017b). Conventional control prevented the population increase but could not reduce the mealybug density, whereas mating disruption promoted a gradual pest decrease when applied consecutively over the years. At lower pest densities, stand-alone application of mating disruption proved to be effective in reducing the population density and grape damage at harvest over years (Sharon et al. 2016; Lucchi et al. 2019). A potential constraint for the effective control of high mealybug populations with the mating disruption technique is represented by its highly aggregated distribution, as clumped colonies increase the probability of casual matings (Cardé and Minks 1995). 
To optimize the efficacy of VMB mating disruption, an integrated sustainable management protocol similar to that of the European grapevine moth should be developed. In fact, mating disruption against $L$. botrana is implemented by visual monitoring of cluster infestation in the first generation, and (bio)insecticide are applied against second-generation larvae when the action threshold of 5-10\% of infested clusters is exceeded in the first generation (Charmillot and Pasquier 2000; Ioriatti et al. 2011). The integration with sustainable control tactics directed to reduce the mealybug density below an economic action threshold would improve the effectiveness of mating disruption for P. ficus. In this perspective, citrus essential oils and paraffin oil seem the most promising compounds allowed in organic viticulture.

Where applied, biological control of the VMB mostly relies on releases of $A$. pseudococci s.l. and $C$. montrouzieri, whereas releases of other natural enemies only occur in limited areas, such as lacewings in California and C. perminutus and Nephus spp. in South Africa (D. Haviland, University of California, Koppert South Africa, pers. comm.). Effective control of $P$. ficus by the combined release of natural enemies has been reported (Lucchi and Benelli 2018). In contrast, biological control trials carried out in California provided inconclusive results despite the mass release of an economically unsustainable number of parasitoids (24,700-37,000 A. pseudococci per hectare) (Daane et al. 2006a; Tollerup 2007). Further studies should clarify the effectiveness of A. pseudococci and A. vladimiri, highlighting constraining factors limiting the natural enemy activity and optimal release rates and timing. In high-value grape productions, a further development may be represented by release of natural enemies through drones equipped with controlled-release devices in order to increase the release efficiency and timing (Neuman 2019). In any case, augmentative or conservation biological control programs of $P$. ficus should include control efforts against mealybug-tending ants, which play a key role in the parasitoid activity. In fact, in several studies, ant suppression resulted in increased parasitism rates and reduced mealybug density and crop damage (Daane et al. 2008b; Mgocheki and Addison 2010; Cooper et al. 2019). Integration of mating disruption and biological control was shown to be possible (Shapira et al. 2018b). In the perspective of future climate change scenarios, contrasting the movement of mealybugs to shelters (spatial refuge) and effective control of tending ants that hinder the foraging activity of natural enemies (temporal refuge) are key points required for a successful control of $P$. ficus (Gutierrez et al. 2008).

Control programs applied in organic viticulture strongly depend on the grape production, as table grape is of high value and high efforts are undertaken to keep the pest density low, whereas wine grape is a medium-value production and some mealybug density is tolerated, and finally raisin grape is a low-value product and mealybug control is limited. Differences in crop value, pest tolerance and pest pressure affect the choice of management strategies. In Europe, mating disruption rope and membrane dispensers cost about $185 € /$ ha when applied at rates recommended by manufacturers (500 units/ha) (CBC Iberia, pers. comm.), whereas 1000 parasitoids/ha or 500 C. montrouzieri beetles/ha have an economic impact of about 115-135 €/ha (Lucchi and Benelli 2018; A. Lucchi, unpubl. data; Koppert Italy, pers. comm.). In California, membrane dispensers cost for about 300 \$/ ha, whereas the flowable formulation is less expensive as a single application costs approximately 75 \$/ha (D. Haviland, University of California, pers. comm.). The cost of deployment of natural enemies and dispensers vary widely among grape-growing regions and cannot be estimated, whereas the microencapsulated formulation is more flexible and is usually tank-mixed with other control products. A single release of $625 \mathrm{~A}$. pseudococci s.1./ha costs 125 \$, whereas the release of $1250 \mathrm{C}$. montrouzieri/ha costs about $100 \$$ (Associates Insectary 2020).

\section{Conclusions and future perspectives}

Synthetic insecticides cannot be employed in pest management programs in organic viticulture. However, a number of control tactics that are environmentally friendly, economically sustainable and safe for human health can be integrated. In this scenario, chemical pesticide-free control tactics for $P$. ficus extend from classical biological control to entomopathogens, including cultural and physical control tactics, mating disruption and bioinsecticides, indicating a wide range of options for successful management programs. Several techniques have been applied effectively in laboratory and field conditions, although few studies investigated their implementation and the economic feasibility of their integration. Therefore, multiple applied research approaches are required to enhance the sustainable control of $P$. ficus in vineyards. This includes understanding of the density action threshold below which biological control and mating disruption are effective as a stand-alone control tactic, as the control effort exerted may change in relation with the magnitude of the pest infestation. The number of released natural enemies and the concentration of mating disruption pheromone dispensers should be adapted to different densities of mealybugs in the vineyard, in agreement with the principles of precision pest control. Additionally, research on cost-effectiveness of integration of the available control methods should also receive attention. Basic research aiming at improving the current knowledge on the modes of action of the available chemical pesticide-free control tools should also be extended to enhance their effectiveness. Improvements in technology, equipment and industrial production, 
such as mass rearing techniques and pheromone synthesis and processing, would reduce the costs of these control tactics thereby contributing to their further spread. Finally, studies on biotic and abiotic factors affecting organic control practices should avoid unexpected failures in pest control. Gathered all together, the studies reviewed indicate the potential implementation of effective management programs for sustainable grape production in the coming years.

\section{Authors' contributions}

AC, ALu and ALe conceived the review; AC, VPS and GB collected the literature; AC, VPS, GB, ALu and ALe analyzed the literature; AC, VPS, GB, ALu and ALe wrote the manuscript. All authors made critical contributions to the draft and gave final approval for publication.

Acknowledgements The authors gratefully acknowledge David Haviland (University of California) for sharing his knowledge of $P$. ficus management in table grapes in California, and Paolo Banzato (Koppert Italy), Brett Chandler (Associates Insectary), Ignacio De Alfonso (Suterra), Stefano Foschi (Bioplanet), Marcela Gonzalez (INTA), Andreas Neuman (UAV-IQ), Paolo Sambado (CBC Iberia), Vittorio Veronelli (CBC Europe) and Louw Viljoen (Koppert South Africa) for providing valuable data on the real-world use of mating disruption and biological control agents. The authors appreciate the constructive comments of three anonymous reviewers that significantly improved this manuscript.

Funding Open access funding provided by Università di Pisa within the CRUI-CARE Agreement.

\section{Compliance with ethical standards}

Conflict of interest The authors declare no competing interests. Mention of trade names or commercial products in this publication is solely for providing specific information and does not imply recommendation or endorsement by the authors' institutions.

Open Access This article is licensed under a Creative Commons Attribution 4.0 International License, which permits use, sharing, adaptation, distribution and reproduction in any medium or format, as long as you give appropriate credit to the original author(s) and the source, provide a link to the Creative Commons licence, and indicate if changes were made. The images or other third party material in this article are included in the article's Creative Commons licence, unless indicated otherwise in a credit line to the material. If material is not included in the article's Creative Commons licence and your intended use is not permitted by statutory regulation or exceeds the permitted use, you will need to obtain permission directly from the copyright holder. To view a copy of this licence, visit http://creativecommons.org/licenses/by/4.0/.

\section{References}

Addison P (2002) Chemical stem barriers for the control of ants (Hymenoptera: Formicidae) in vineyards. S Afr J Enol Vitic 23:1-8
Addison P, Samways MJ (2000) A survey of ants (Hymenoptera: Formicidae) that forage in vineyards in the Western Cape Province, South Africa. Afr Entomol 8:251-260

Addison P, Samways J (2012) Ecological management of ants in vineyards of the Cape Floristic region biodiversity hotspot, South Africa. In: Bostanian N, Vincent C, Isaacs R (eds) Arthropod management in vineyards: pests, approaches, and future directions. Springer, Dordrecht, pp 37-52

Ag Innovations (2020) Towards safer and more sustainable alternatives to chlorpyrifos: an action plan for California. https://www. cdpr.ca.gov/docs/chlorpyrifos/pdf/chlorpyrifos_action_plan.pdf. Accessed 10 Sep 2020

Amala U, Yadav DS, Bhosale AM (2013) Studies on parasitoid complex of mealybug infesting grapes in Maharashtra. J Appl Hortic 15:117-119

Andreason SA, Triapitsyn SV, Perring TM (2019) Untangling the Anagyrus pseudococci species complex (Hymenoptera: Encyrtidae), parasitoids of worldwide importance for biological control of mealybugs (Hemiptera: Pseudococcidae): Genetic data corroborates separation of two new, previously misidentified species. Biol Control 129:65-82

Associates Insectary (2020) Vine mealybug (VMB) control. http:// www.associatesinsectary.com/organism/mealybug-destroyer/ Accessed 10 September 2020

Athanassiou CG, Kavallieratos NG, Benelli G, Losic D, Usha Rani P, Desneux N (2018) Nanoparticles for pest control: current status and future perspectives. J Pest Sci 91:1-15

Attia AR (2012) Hymenpterous parasitoids as a bioagents for controlling maybugs (Hemiptera: Pseudococcidae) in Egypt. Egypt Acad J Biolog Sci 5:183-192

Baba A, Erina O, Tatsuya H, Ryuichi S, Kinsho T (2019) Development of the dual purpose mating disruption dispenser to control both the European grapevine moth, Lobesia botrana, and the vine mealybug, Planococcus ficus, in vineyards. In: Book of abstracts PheroFIP, 20-25 January 2019, Lisbon, Portugal, p 176

Becerra V, González M, Herrera ME, Miano JL (2006) Dinámica poblacional de Planococcus ficus Sign. (Hemiptera - Pseudococcidae) en vĩnedos. Mendoza (Argentina). Rev Fac Cien Agrar Univ Nac Cuyo 38:1-6

Beltrà A, Navarro-Campos C, Calabuig A, Estopà L, Wäckers FL, Pekas A, Soto A (2017) Association between ants (Hymenoptera: Formicidae) and the vine mealybug (Hemiptera: Pseudococcidae) in table-grape vineyards in Eastern Spain. Pest Manag Sci 73:2473-2480

Ben-Dov Y, Matile-Ferrero D (1995) The identity of the mealybug taxa described by V.A. Signoret (Homoptera, Coccoidea, Pseudococcidae). Bull Soc Ent France 100:241-256

Benelli G, Giunti G, Tena A, Desneux N, Caselli A, Canale A (2017) The impact of adult diet on parasitoid reproductive performance. J Pest Sci 90:807-823

Benelli G, Pavela R, Zorzetto C, Sánchez-Mateo CC, Santini G, Canale A, Maggi F (2019) Insecticidal activity of the essential oil from Schizogyne sericea (Asteraceae) on four insect pests and two non-target species. Entomol Gen 39:9-18

Berlinger MJ (1977) The Mediterranean vine mealybug and its natural enemies in southern Israel. Phytoparasitica 5:3-14

Bertin S, Pacifico D, Cavalieri V, Marzachì C, Bosco D (2016) Transmission of Grapevine virus A and Grapevine leafroll-associated viruses 1 and 3 by Planococcus ficus and Planococcus citri fed on mixed-infected plants. Ann Appl Biol 169:53-63

Biondi A, Desneux N, Siscaro G, Zappalà L (2012) Using organiccertified rather than synthetic pesticides may not be safer for biological control agents: selectivity and side effects of 14 pesticides on the predator Orius laevigatus. Chemosphere 87:803-812

Bordeu E, Troncoso DO, Zaviezo T (2012) Influence of mealybug (Pseudococcus spp.)-infested bunches on wine quality 
in Carmenere and Chardonnay grapes. Int J Food Sci Technol 47:232-239

Brillante L, Belfiore N, Gaiotti F, Lova L, Sansone L, Poni S, Tomasi D (2016) Comparing kaolin and pinolene to improve sustainable grapevine production during drought. PLoS ONE 11(6):e0156631

Brück E, Elbert A, Fischer R, Krueger S, Kühnhold J, Klueken AM et al (2009) Movento ${ }^{\circledR}$, an innovative ambimobile insecticide for sucking insect pest control in agriculture: biological profile and field performance. Crop Prot 28:838-844

Bugila AA, Branco M, Silva EBD, Franco JC (2014) Host selection behaviour and specificity of the solitary parasitoid of mealybugs Anagyrus sp. nr. pseudococci (Girault) (Hymenoptera, Encyrtidae). Biocontrol Sci Technol 24:22-38

Bugila AA, Franco JC, Silva EBD, Branco M (2014) Defense response of native and alien mealybugs (Hemiptera: Pseudococcidae) against the solitary parasitoid Anagyrus sp. nr. pseudococci (Girault) (Hymenoptera: Encyrtidae). J Insect Behav 27:439-453

CDPR (California Department of Pesticide Regulation) (2020) Chlorpyrifos Cancellation. https://www.cdpr.ca.gov/docs/chlorpyrifos/ index.htm. Accessed 10 September 2020

Cabaleiro C, Couceiro C, Pereira S, Cid M, Barrasa M, Segura A (2008) Spatial analysis of epidemics of Grapevine leafroll associated virus-3. Eur J Plant Pathol 121:121-130

Cabaleiro C, Pesqueira AM, Barrasa M, Garcia-Berrios JJ (2013) Analysis of the losses due to grapevine leafroll disease in Albariño vineyards in Rias Baixas (Spain). Ciência e Técnica Vitivinícola 28:43-50

Caboni P, Cabras P (2010) Pesticides' influence on wine fermentation. In: Taylor SL (ed) Advances in food and nutrition research, vol 59. Academic Press, Burlington, pp 43-62

Campos JM, Martínez-Ferrer MT, Forés V (2006) Parasitism disruption by ants of Anagyrus pseudococci (Girault) and Leptomastix dactylopii Howard (Hymenoptera: Encyrtidae), two parasitoids of the citrus mealybug Planococcus citri (Risso) (Homoptera: Pseudococcidae). IOBC-WPRS Bull 29(3):33-46

Cardé R, Minks A (1995) Control of moth pests by mating disruption: successes and constraints. Annu Rev Entomol 40:559-585

Cavalieri V, Mazzeo G, Garzia GV, Buonocore E, Russo A (2008) Identification of Planococcus ficus and Planococcus citri (Hemiptera: Pseudococcidae) by PCR-RFLP of COI gene. Zootaxa 1816:65-68

Chailleux A, Stirnemann A, Leyes J, Deletre E (2019) Manipulating natural enemy behavior to improve biological control: attractants and repellents of a weaver ant. Entomol Gen 38:191-210

Charles JG, Cohen D, Walker JTS, Forgie SA, Bell VA, Breen KC (2006) A review of the ecology of grapevine leafroll associated virus type 3 (GLRaV-3). NZ Plant Prot 59:330-337

Charles JG, Froud KJ, van den Brink R, Allan DJ (2009) Mealybugs and the spread of grapevine leafroll-associated virus 3 (GLRaV3 ) in a New Zealand vineyard. Aust Plant Pathol 38:576-583

Charmillot PJ, Pasquier D (2000) Lutte par confusion contre les vers de la grappe: succès et problèmes rencontrés. IOBC-WPRS Bull 23(4):145-147

Chiotta ML, Ponsone ML, Torres AM, Combina M, Chulze SN (2010) Influence of Planococcus ficus on Aspergillus section Nigri and ochratoxin A incidence in vineyards from Argentina. Lett Appl Microbiol 51:212-218

Choe D-H, Tsai K, Lopez CM, Campbell K (2014) Pheromone-assisted techniques to improve the efficacy of insecticide sprays against Linepithema humile (Hymenoptera: Formicidae). J Econ Entomol 107:319-325

Cid M, Pereiro S, Cabaleiro C, Segura A (2010) Citrus mealybug (Hemiptera: Pseudococcidae) movement and population dynamics in an arbor-trained vineyard. J Econ Entomol 103:619-630
Cocco A, Lentini A, Serra G (2014) Mating disruption of Planococcus ficus (Hemiptera: Pseudococcidae) in vineyards using reservoir pheromone dispensers. J Insect Sci 14:144

Cocco A, Marras MP, Muscas E, Mura A, Lentini A (2015) Variation of life-history parameters of Planococcus ficus (Hemiptera: Pseudococcidae) in response to grapevine nitrogen fertilization. J Appl Entomol 139:519-528

Cocco A, Mura A, Muscas E, Lentini A (2018) Comparative development and reproduction of Planococcus ficus and Planococcus citri (Hemiptera: Pseudococcidae) on grapevine under field conditions. Agric For Entomol 20:104-112

Cocco A, Muscas E, Mura A, Iodice A, Savino F, Lentini A (2018) Influence of mating disruption on the reproductive biology of the vine mealybug, Planococcus ficus (Hemiptera: Pseudococcidae), under field conditions. Pest Manag Sci 74:2806-2816

Cooper ML, Daane KM, Nelson EH, Varela LG, Battany MC, Tsutsui ND, Rust MK (2008) Liquid baits manage Argentine ants in coastal vineyards. Calif Agric 62:177-183

Cooper ML, Hobbs MB, Boser CL, Varela LG (2019) Argentine ant management: using toxin-laced polyacrylamide crystals to target ant colonies in vineyards. Catal Discov Pract 3:23-30

Cooper ML, Varela LG, Smith RJ, Whitmer DR, Simmons GA, Lucchi A, Broadway R, Steinhauer R (2014) Growers, scientists and regulators collaborate on European grapevine moth program. Calif Agric 4:125-133

Costello MJ, Daane KM (1999) Abundance of spiders and insect predators on grapes in central California. J Arachnol 27:531-538

Costello MJ, Welch MD (2014) Influence of weeds on Argentine ant (Hymenoptera: Formicidae) and obscure mealybug (Hemiptera: Pseudococcidae) in a central California vineyard. J Econ Entomol 107:1194-1200

Cox JM (1989) The mealybug genus Planococcus (Homoptera: Pseudococcidae). Bull Br Museum Natural Hist Entomol 58:1-78

Cox JM, Ben-Dov Y (1986) Planococcine mealybugs of economic importance from the Mediterranean Basin and their distinction from a new African genus (Hemiptera: Pseudococcidae). Bull Entomol Res 76:481-489

Cox JM, Pearce MJ (1983) Wax produced by dermal pores in three species of mealybug (Homoptera: Pseudococcidae). Int J Insect Morphol Embryol 12:235-248

Cox JM, Wetton JM (1988) Identification of the mealybug Planococcus halli Ezzat and McConnell (Hemiptera: Pseudococcidae) commonly occurring on yams (Dioscorea spp.) in Africa and the West Indies. Bull Entomol Res 78:561-571

Cucchi NJA, Becerra V Gonzalez MF (2009) Cochinilla harinosa de la vid o chanchito blanco de la vid Planococcus ficus (= Coccus vitis, Pseudococcus vitis). In: Cucchi NJA, Becerra V (eds) Manual de tratamientos fitosanitarios para cultivos de clima templado bajo riego: vid. Ediciones INTA, pp 71-85

Daane KM, Almeida RPP, Bell VA, Walker JTS, Botton M, Fallahzadeh $M$ et al (2012) Biology and management of mealybugs in vineyards. In: Bostanian N, Vincent C, Isaacs R (eds) Arthropod management in vineyards: pests, approaches, and future directions. Springer, Dordrecht, pp 271-307

Daane K, Bentley W, Walton V et al (2006) New controls investigated for vine mealybug. Calif Agric 60:31-38

Daane KM, Cooper ML, Sime KR, Nelson E, Battany MC, Rust MK (2008) Testing baits to control Argentine ants (Hymenoptera: Formicidae) in vineyards. J Econ Entomol 10:699-709

Daane KM, Cooper ML, Triapitsyn SV, Walton V, Yokota GY, Haviland DR et al (2008) Vineyard managers and researchers seek sustainable solutions for mealybugs, a changing pest complex. Calif Agric 62:167-176

Daane KM, Hogg BN, Wilson H, Yokota GY (2018) Native grass ground covers provide multiple ecosystem services in Californian vineyards. J Appl Ecol 55:2473-2483 
Daane KM, Malakar-Kuenen RD, Walton VM (2004) Temperaturedependent development of Anagyrus pseudococci (Hymenoptera: Encyrtidae) as a parasitoid of the vine mealybug, Planococcus ficus (Homoptera: Pseudococcidae). Biol Control 31:123-132

Daane KM, Middleton MC, Sforza R, Cooper ML, Walton VM et al (2011) Development of a multiplex PCR for identification of vineyard mealybugs. Environ Entomol 40:1595-1603

Daane KM, Middleton MC, Sforza RF, Kamps-Hughes N, Watson GW et al (2018) Determining the geographic origin of invasive populations of the mealybug Planococcus ficus based on molecular genetic analysis. PLoS ONE 13(3):e0193852

Daane KM, Sime KR, Cooper ML, Battany MC (2004) Ants in your vineyard? UC Plant Prot Quart 11(2):1-3

Daane KM, Sime KR, Fallon J, Cooper ML (2007) Impacts of Argentine ants on mealybugs and their natural enemies in California's coastal vineyards. Ecol Entomol 32:583-596

Daane KM, Sime KR, Hogg BN, Bianchi ML, Cooper ML, Rust MK, Klotz JH (2006) Effects of liquid insecticide baits on Argentine ants in California's coastal vineyards. Crop Prot 25:592-603

Daane KM, Vincent C, Isaacs R, Ioriatti C (2018) Entomological opportunities and challenges for sustainable viticulture in a global market. Annu Rev Entomol 63:193-214

Daane KM, Yokota GY, Walton VM, Hogg BN et al (2020) Development of a mating disruption program for a mealybug, Planococcus ficus, in vineyards. Insects 11:635

Daane KM, Malakar-Kuenen R, Guillén M, Bentley WJ, Bianchi M, Gonzalez D (2003) Abiotic and biotic pest refuges hamper biological control of mealybugs in California vineyards. In: Proceedings of $1^{\text {st }}$ International Symposium of Biological Control of Arthropods, 14-18 January 2002, Honolulu, USA, pp 389-398

Daane K, Weber E, Bentley W (2004) Formidable pest spreading through California vineyards. Practical Winery \& Vineyard May-June 2004:1-4

Dalla Montà L, Duso C, Malagnini V (2001) Current status of scale insects (Hemiptera: Coccoidea) in the Italian vineyards. Boll Zool Agr Bachic 33:343-350

Damien M, Le Lann C, Desneux N, Alford L, Al Hassan D, Georges $R$, Van Baaren J (2017) Flowering cover crops in winter increase pest control but not trophic link diversity. Agric Ecosyst Environ 247:418-425

Davies AP, Ceballo FA, Walter GH (2004) Is the potential of Coccidoxenoides perminutus, a mealybug parasitoid, limited by climatic or nutritional factors? Biol Control 31:181-188

Delabie JHC (2001) Trophobiosis between Formicidae and Hemiptera (Sternorrhyncha and Auchenorrhyncha): an overview. Neotrop Entomol 30:501-516

Demontis MA, Ortu S, Cocco A, Lentini A, Migheli Q (2007) Diagnostic markers for Planococcus ficus (Signoret) and Planococcus citri (Risso) by random amplification of polymorphic DNA-polymerase chain reaction and species-specific mitochondrial DNA primers. J Appl Entomol 131:59-64

Desneux N, Decourtye A, Delpuech JM (2007) The sublethal effects of pesticides on beneficial arthropods. Annu Rev Entomol 52:81-106

Deza-Borau G, Peschiutta ML, Brito VD, Usseglio VL, Zunino MP, Zygadlo JA (2020) Towards a development of novel bioinsecticides for organic control of Planococcus ficus in vineyards. Vitis 59:127-132

Duso C (1989) Bioecological study on Planococcus ficus (Sign.) in Veneto. Boll Lab Entomol Agr Filippo Silvestri 46:3-20 (in Italian)

European Union (2009a) Regulation (EC) No 1107/2009. Off J Eur Comm L 309:1-50

European Union (2009b) Directive 2009/128/EC. Off J Eur Comm L 309:71-86
European Union (2018a) Commission implementing regulation (EU) 2018/783. Off J Eur Union L 132:31-34

European Union (2018b) Commission implementing regulation (EU) 2018/784. Off J Eur Union L 132:35-39

European Union (2018c) Commission implementing regulation (EU) 2018/785. Off J Eur Union L 132:40-44

European Union (2020a) Commission implementing regulation (EU) 2020/17. Off J Eur Union L 7:11-13

European Union (2020b) Commission implementing regulation (EU) 2020/18. Off J Eur Union L 7:14-16

FAOSTAT (2018) Statistical database. http://www.fao.org/faostat/ en/\#data/QC. Accessed 08 August 2018

Fallahzadeh M, Japoshvili G (2010) Checklist of Iranian Encyrtids (Hymenoptera: Chalcidoidea) with descriptions of new species. J Insect Sci 10:68

Fallahzadeh M, Japoshvili G, Saghaei N, Daane KM (2011) Natural enemies of Planococcus ficus (Hemiptera: Pseudococcidae) in Fars province vineyards, Iran. Biocontrol Sci Technol 21:427-433

Feng D-D, Michaud JP, Li P, Zhou Z-S, Xu Z-F (2015) The native ant, Tapinoma melanocephalum, improves the survival of an invasive mealybug, Phenacoccus solenopsis, by defending it from parasitoids. Sci Rep 5:15691

Flint ML (2016) Pest Notes: Mealybugs. UC ANR Publication 74174 http://ipm.ucanr.edu/PMG/PESTNOTES/pn74174.html Accessed 28 August 2020

Franco JC, Gross S, Silva EB, Suma P, Russo A, Mendel Z (2003) Is mass-trapping a feasible management tactic of the citrus mealybug in citrus orchard? Anais Inst Super Agron 49:353-367

Franco JC, Silva EB, Cortegano E, Campos L, Branco M, Zada A, Mendel Z (2008) Kairomonal response of the parasitoid Anagyrus spec. nov. near pseudococci to the sex pheromone of the vine mealybug. Entomol Exp Appl 126:122-130

Franco JC, Silva EB, Fortuna E, Cortegano E, Branco M, Suma P et al (2011) Vine mealybug sex pheromone increases citrus mealybug parasitism by Anagyrus sp. near pseudococci (Girault). Biol Control 58:230-238

Franco JC, Suma P, Da Silva EB, Blumberg D, Mendel Z (2004) Management strategies of mealybug pests of citrus in Mediterranean countries. Phytoparasitica 32:507-522

Franco JC, Zada A, Mendel Z (2009) Novel approaches for the management of mealybug pests. In: Ishaaya I, Horowitz AR (eds) Biorational control of arthropod pests. Springer, Dordrecht, pp $233-278$

Fruitos A, González M, Alemanno V, Mazzitelli ME, Aquino D, Debandi G (2019) Parasitoides e hiperparasitoides de Planococcus ficus (Hemiptera: Pseudococcidae) en viñedos de Barrancas, Mendoza. Semiárida 29:23-25

García Morales M, Denno BD, Miller DR, Miller GL, Ben-Dov Y, Hardy NB (2016) ScaleNet: A literature-based model of scale insect biology and systematics. Database. http://scalenet.info. Accessed on 08 August 2018

Geiger CA, Daane KM (2001) Seasonal movement and distribution of the grape mealybug (Homoptera: Pseudococcidae): developing a sampling program for San Joaquin Valley vineyards. J Econ Entomol 94:291-301

Gonzalez Luna MF, La Rossa FR (2016) Parámetros biológicos y poblacionales de Planococcus ficus (Hemiptera: Pseudococcidae) sobre dos cultivares de Vitis vinifera. Rev Soc Entomol Argentina 75:45-54

Gonçalves F, Zina V, Carlos C, Crespo L, Oliveira I, Torres L (2017) Ants (Hymenoptera: Formicidae) and spiders (Araneae) cooccurring on the ground of vineyards from Douro Demarcated Region. Sociobiology 64:404-416

Gullan PJ, Kosztarab M (1997) Adaptations in scale insects. Annu Rev Entomol 42:23-50 
Gutierrez AP, Daane KM, Ponti L, Walton VM, Ellis CK (2008) Prospective evaluation of the biological control of vine mealybug: refuge effects and climate. J Appl Ecol 45:524-536

Güleç G, Kilinçer AN, Kaydan MB, Ülgentürk S (2007) Some biological interactions between the parasitoid Anagyrus pseudococci (Girault) (Hymenoptera: Encyrtidae) and its host Planococcus ficus (Signoret) (Hemiptera: Coccoidea: Pseudococcidae). J Pest Sci 80:43-49

Haviland DR, Bentley WJ, Daane KM (2005) Hot-water treatments for control of Planococcus ficus (Homoptera: Pseudococcidae) on dormant grape cuttings. J Econ Entomol 98:1109-1115

Haviland DR (2017) Mating disruption of vine mealybug, Planococcus ficus, using sprayable microencapsulated pheromone in California table grapes. Proceedings "Future IPM 3.0 towards a sustainable agriculture", 15-20 October 2017, Riva del Garda, Italy, pp 190-191

Heidari M, Copland MJW (1992) Host finding by Cryptolaemus montrouzieri (Col., Coccinellidae) a predator of mealybugs (Hom., Pseudococcidae). Entomophaga 37:621-625

Herrero-Hernández E, Andrades MS, Álvarez-Martín A, Pose-Juan E, Rodríguez-Cruz MS, Sánchez-Martín MJ (2013) Occurrence of pesticides and some of their degradation products in waters in a Spanish wine region. J Hydrol 486:234-245

Herrero-Hernández E, Rodríguez-Cruz MS, Pose-Juan E, SánchezGonzález S, Andrades MS, Sánchez-Martín MJ (2017) Seasonal distribution of herbicide and insecticide residues in the water resources of the vineyard region of La Rioja (Spain). Sci Total Environ 609:161-171

Hinkens DM, McElfresh SJ, Millar JG (2001) Identification and synthesis of the sex pheromone of the vine mealybug Planococcus ficus. Tetrahedron Lett 42:1619-1621

Hussey NW, Scopes N (1985) Biological pest control. Cornell University Press, Ithaca

Ioriatti C, Anfora G, Tasin M, De Cristofaro A, Witzgall P, Lucchi A (2011) Chemical ecology and management of Lobesia botrana (Lepidoptera: Tortricidae). J Econ Entomol 104:1125-1137

Ioriatti C, Lucchi A (2016) Semiochemical strategies for tortricid moth control in apple orchards and vineyards in Italy. J Chem Ecol 42:571-583

Irvin NA, Hoddle MS (2015) The effect of buckwheat flowers and cahaba vetch on fitness of the vine mealybug parasitoid Anagyrus pseudococci (Hymenoptera: Encyrtidae). Fla Entomol 98:237-242

Italian Ministry of Health (2020) Banca dati dei prodotti fitosanitari. http://www.fitosanitari.salute.gov.it/fitosanitariwsWeb_new/Fitos anitariServlet. Accessed 12 March 2020

Japoshvili G, Erkılıç L, Çalışkan AF, Kaydan MB (2018) Parasitoid complex of Planococcus ficus (Signoret) (Hemiptera: Pseudococcidae) in Turkey. Phytoparasitica 46:481-485

KCDA (Kern County Department of Agriculture) (2020) Kern County Permit/Use Data, 2009-2020. http://www.kernag.com/ep/permi t-use/permit-use.asp. Accessed on 15 September 2020

Karamaouna F, Kimbaris A, Michaelakis A, Papachristos D, Polissiou M, Papatsakona P et al (2013) Insecticidal activity of plant essential oils against the vine mealybug, Planococcus ficus. J Insect Sci 13:142

Karamaouna F, Menounou G, Stathas GJ, Avtzis DN (2011) First record and molecular identification of the parasitoid Anagyrus sp. near pseudococci Girault (Hymenoptera: Encyrtidae) in Greece - Host size preference for the vine mealybug Planococcus ficus (Signoret) (Hemiptera: Pseudococcidae). Hell Plant Prot J 4:45-52

Kaydan MB, Kilinçer N, Uygun N, Japoshvili G, Gaimari S (2006) Parasitoids and predators of Pseudococcidae (Hemiptera: Coccoidea) in Ankara, Turkey. Phytoparasitica 34:331-337
Khandakar SI, Jahan M (1993) Influence of honeydew of citrus mealybug (Planococcus citri) on searching behaviour of its parasitoid, Anagyrus pseudococci. Indian J Agric Sci 63:743-746

Kol-Maimon H, Ghanim M, Franco JC, Mendel Z (2015) Evidence for gene flow between two sympatric mealybug species (Insecta; Coccoidea; Pseudococcidae). PLoS ONE 9(2):e88433

Kreiter S (2018) Pest management in organic grape production. In: Vacante V, Kreiter S (eds) Handbook of pest management in organic farming. CABI, Oxfordshire, pp 173-217

Langone D, Kurtural SK, Daane KM (2014) Mating disruption of vine mealybug. Practical Winery \& Vineyard February 2014:1-3

Lentini A, Mura A, Muscas E, Nuvoli MT, Cocco A (2018) Effects of delayed mating on the reproductive biology of the vine mealybug, Planococcus ficus (Hemiptera: Pseudococcidae). Bull Entomol Res 108:263-270

Lentini A, Serra G, Ortu S, Delrio G (2008) Seasonal abundance and distribution of Planococcus ficus on grape vine in Sardinia. IOBC-WPRS Bull 36:267-272

Lernoud J, Willer H (2018) Land use and key commodities in organic agriculture. In Willer H, Lernoud J (eds) The world of organic agriculture. Statistics and Emerging Trends 2018. Research Institute of Organic Agriculture (FiBL), Frick, pp 74-125

Levi-Zada A, Fefer D, David M, Eliyahu M, Franco JC, Protasov A, Dunkelblum E, Mendel Z (2014) Diel periodicity of pheromone release by females of Planococcus citri and Planococcus ficus and the temporal flight activity of their conspecific males. Naturwissenschaften 101:671-678

Linder C, Rösti J, Lorenzini F, Deneulin P, Badertscher R, Kehrli P (2020) Efficacy of kaolin treatments against Drosophila suzukii and their impact on the composition and taste of processed wines. Vitis 59:49-52

Liu YB, Bettiga LJ, Daane KM (2010) Ultralow oxygen treatment for control of Planococcus ficus (Hemiptera: Pseudococcidae) on grape benchgrafts. J Econ Entomol 103:272-276

Lucchi A, Benelli G (2018) Towards pesticide-free farming? Sharing needs and knowledge promotes Integrated Pest Management. Environ Sci Pollut Res 14:13439-13445

Lucchi A, Suma P, Ladurner E, Iodice A, Savino F, Ricciardi R, Cosci F, Marchesini E, Conte G, Benelli G (2019) Managing the vine mealybug, Planococcus ficus, through pheromone-mediated mating disruption. Environ Sci Pollut Res 26:10708-10718

Mahfoudhi N, Dhouibi MH (2009) Survey of mealybugs (Hemiptera: Pseudococcidae) and their natural enemies in Tunisian vineyards. Afr Entomol 17:154-160

Maia MF (2013) Cochonilhas em vinha. Potencialidades de interacção com os níveisde fertilização da vinha e tipos de poda. Master Thesis dissertation, Universidade Técnica de Lisboa

Malausa T, Fenis A, Warot S, Germain JF, Ris N, Prado E et al (2011) DNA markers to disentangle complexes of cryptic taxa in mealybugs (Hemiptera: Pseudococcidae). J Appl Entomol 135:142-155

Mansour R, Belzunces LP, Suma P, Zappalà L, Mazzeo G, GrissaLebdi $\mathrm{K}$ et al (2018) Vine and citrus mealybug pest control based on synthetic chemicals. A review. Agron Sustain Dev 38:37

Mansour R, Grissa-Lebdi K, Khemakhem M, Chaari I, Trabelsi I, Sabri A, Marti S (2017) Pheromone-mediated mating disruption of Planococcus ficus (Hemiptera: Pseudococcidae) in Tunisian vineyards: Effect on insect population dynamics. Biologia 72:333-341

Mansour R, Grissa-Lebdi K, Suma P, Mazzeo G, Russo A (2017) Key scale insects (Hemiptera: Coccoidea) of high economic importance in a Mediterranean area: host plants, bio-ecological characteristics, natural enemies and pest management strategies-a review. Plant Prot Sci 53:1-14

Mansour R, Lebdi KG, Rezgui S (2010) Assessment of the performance of some new insecticides for the control of the vine 
mealybug Planococcus ficus in a Tunisian vineyard. Entomol Hell 19:21-33

Mansour R, Mazzeo G, Pergola A, Grissa Lebdi K, Russo A (2011) A survey of scale insects (Hemiptera: Coccoidea) and tending ants in Tunisian vineyards. J Plant Prot Res 51:197-203

Mansour R, Suma P, Mazzeo G, Buonocore E, Grissa Lebdi K, Russo A (2010) Using a kairomone-based attracting system to enhance biological control. J Entomol Acarol Res 42:161-170

Mansour R, Suma P, Mazzeo G, Grissa Lebdi K, Russo A (2011) Evaluating side effects of newer insecticides on the vine mealybug parasitoid Anagyrus sp. near pseudococci, with implications for integrated pest management in vineyards. Phytoparasitica 39:369-376

Mansour R, Suma P, Mazzeo G, La Pergola A, Pappalardo V, Grissa Lebdi K, Russo A (2012) Interactions between the ant Tapinoma nigerrimum (Hymenoptera: Formicidae) and the main natural enemies of the vine and citrus mealybugs (Hemiptera: Pseudococcidae). Biocontrol Sci Technol 22:527-537

Marras PM, Cocco A, Muscas E, Lentini A (2016) Laboratory evaluation of the suitability of vine mealybug, Planococcus ficus, as a host for Leptomastix dactylopii. Biol Control 95:57-65

Marrone PG (2019) Pesticidal natural products-status and future potential. Pest Manag Sci 75:2325-2340

Marrone PG (2011) Two new species of bacteria: MBI-203 $\left(\right.$ Grandevo ${ }^{\circledR}$ ) and MBI-206 insecticides. Annual Biocontrol Industry Meeting (ABIM), 24-26 October 2011, Lucerne, Switzerland. https://www.abim.ch/fileadmin/abim/documents/prese ntations2011/Session4/8_Pamela_Marrone_ABIM2011.pdf Accessed 4 September 2020

Masoni A, Frizzi F, Brühl C, Zocchi N, Palchetti E, Chelazzi G, Santini G (2017) Management matters: A comparison of ant assemblages in organic and conventional vineyards. Agric Ecosyst Environ 246:175-183

Mendel Z, Gross S, Steinberg S, Blumberg D (1999) Trials for the control of the citrus mealybug in citrus orchards by augmentative release of two encyrtid parasitoids. Entomologica 33:251-265

Merlin J, Lemaitre O, Gregoire JC (1996) Oviposition in Cryptolaemus montrouzieri stimulated by wax filaments of its prey. Entomol Exp Appl 79:141-146

Mgocheki N, Addison P (2009) Interference of ants (Hymenoptera: Formicidae) with biological control of the vine mealybug Planococcus ficus (Signoret) (Hemiptera: Pseudococcidae). Biol Control 49:180-185

Mgocheki N, Addison P (2010) Spatial distribution of ants (Hymenoptera: Formicidae), vine mealybugs and mealybug parasitoids in vineyards. J Appl Entomol 134:285-295

Mgocheki N, Addison P (2015) The sublethal effects of a systemic insecticide on the vine mealybug parasitoids Anagyrus sp. near pseudococci (Girault) and Coccidoxenoides perminutus (Timberlake) (Hymenoptera: Encyrtidae). S Afr J Enol Vitic 36:175-179

Mgocheki N (2008) The relationship between ants (Hymenoptera: Formicidae), vine mealybug (Hemiptera: Pseudococcidae) and parasitoids in vineyards of the Western Cape Province, South Africa. PhD Thesis dissertation, Stellenbosch University

Miano JL, Becerra VC, Gonzalez MF (2011) Mating disruption for Planococcus ficus S.: how to successfully initiate a novel sustainable control tool. Phytopathology 101:S120

Michaud JP (2018) Challenges to conservation biological control on the High Plains: 150 years of evolutionary rescue. Biol Control 125:65-73

Millar JG, Daane KM, McElfresh JS, Moreira JA, Malakar-Kuenen R, Guillén M, Bentley WJ (2002) Development and optimization of methods for using sex pheromone for monitoring the mealybug Planococcus ficus (Homoptera: Pseudococcidae) in California vineyards. J Econ Entomol 95:706-714
Mohamedova MS, Valcheva IS, Draganova DG, Naydenov MK, Borisov YB (2017) Effect of Bacillus amyloliquefaciens A1, Paenibacillus polymyxa $\mathrm{AB} 3$ and Providencia rettgeri $\mathrm{K} 10$ on the citrus mealybug, Planococcus citri (Risso) (Hemiptera: Pseudococcidae). Egypt J Biol Pest Control 27:41-47

Moloinyane S, Addison P, Achiano KA, Nchu F (2020) Association between chemical properties of vineyard soils and occurrence of entomopathogenic fungi causing different levels of mortality in Planococcus ficus. Biocontrol 65:197-209

Moloinyane S, Nchu F (2019) The effects of endophytic Beauveria bassiana inoculation on infestation level of Planococcus ficus, growth and volatile constituents of potted greenhouse grapevine (Vitis vinifera $\mathrm{L}$.). Toxins 11:72

Muscas E, Cocco A, Mercenaro L, Cabras M, Lentini A, Porqueddu C, Nieddu G (2017) Effects of vineyard floor cover crops on grapevine vigor, yield, and fruit quality, and the development of the vine mealybug under a Mediterranean climate. Agric Ecosyst Environ 237:203-212

Muştu M, Demirci F, Kaydan MB, Ülgentürk S (2015) Laboratory assay of the effectiveness of the entomopathogenic fungus Isaria farinosa (Holmsk.) Fries (Sordariomycetes: Hypocreales) against the vine mealybug Planococcus ficus (Signoret) (Hemiptera: Pseudococcidae), even under the use of fungicides. Int J Pest Manage 61:264-271

Muştu M, Kilinçer N (2014) Intraguild predation of Planococcus ficus parasitoids Anagyrus pseudococci and Leptomastix dactylopii by Nephus kreissli. Biocontrol Sci Technol 24:257-269

Muştu M, Kilinçer N (2015) Interspecific competition between Anagyrus pseudococci and Leptomastix dactylopii, parasitoids of the vine mealybug Planococcus ficus. Biocontrol 60:485-493

Muştu M, Kilinçer N, Ülgentürk S, Kaydan MB (2008) Feeding behavior of Cryptolaemus montrouzieri on mealybugs parasitized by Anagyrus pseudococci. Phytoparasitica 36:360-367

Muştu M, Kılınçer N (2013) Life table and some feeding features of Nephus kreissli fed on Planococcus ficus. Phytoparasitica 41:203-211

Naegele RP, Cousins P, Daane KM (2020) Identification of Vitis cultivars, rootstocks, and species expressing resistance to a Planococcus mealybug. Insects 11:86

Neuman A (2019) The biocontrol brief: How to control mealybugs in your table grape vineyard (part 2). https://www.freshfruitporta 1.com/news/2019/05/29/the-biocontrol-brief-how-to-controlmealybugs-in-your-table-grape-vineyard-part-2/. Accessed 10 September 2020

Niyazov OD (1969) The parasites and predators of grape mealybug. Zashchita Rastenii 14:38-40 ((in Russian))

Nondillo A, Andzeiewski S, Bello Fialho F, Bueno OC, Botton M (2016) Control of Linepithema micans (Hymenoptera: Formicidae) and Eurhizococcus brasiliensis (Hemiptera: Margarodidae) in vineyards using toxic baits. J Econ Entomol 109:1660-1666

Nondillo A, Arioli CJ, Wild A, Bueno OC, Botton M (2017) Myrmecofauna (Hymenoptera: Formicidae) present in vineyards infested with Eurhizococcus brasiliensis (Hemiptera: Margarodidae) in Southern Brazil. Fla Entomol 100:551-557

Nondillo A, Ferrari L, Lerin S, Bueno OC, Botton M (2014) Foraging activity and seasonal food preference of Linepithema micans (Hymenoptera: Formicidae), a species associated with the spread of Eurhizococcus brasiliensis (Hemiptera: Margarodidae). J Econ Entomol 107:1385-1391

Noyes JS, Hayat M (1994) Oriental mealybug parasitoids of the Anagyrini (Hymenoptera: Encyrtidae). CAB International, Wallingford

Noyes JS (2003) Universal Chalcidoidea Database. https://www. nhm.ac.uk/our-science/data/chalcidoids/database/. Accessed 25 August 2020 
Oliveira JEM, Lopes FSC, Oliveira JV, Oliveira MD, Freitas MTS, Balbino VQ (2018) Maconellicoccus hirsutus (Green, 1908) (Hemiptera: Pseudococcidae): exotic pest introduced on vine in the São Francisco Valley. Asian Acad R J Multidiscip 5:30-38

Pacheco da Silva VC, Bertin A, Blin A, Germain JF, Bernardi D, Rignol G et al (2014) Molecular and morphological identification of mealybug species (Hemiptera: Pseudococcidae) in Brazilian vineyards. PLoS ONE 9(7):e103267

Pacheco da Silva V, Galzer ECW, Malausa T, Germain JF, Kaydan MB, Botton M (2016) The vine mealybug Planococcus ficus (Signoret) (Hemiptera: Pseudococcidae) damaging vineyards in Brazil. Neotrop Entomol 45:449-451

Pacheco da Silva VC, Kaydan MB, Malausa T, Germain JF, Palero F, Botton M (2017) Integrative taxonomy methods reveal high mealybug (Hemiptera: Pseudococcidae) diversity in southern Brazilian fruit crops. Sci Rep 7:15741

Pavela R, Benelli G (2016) Essential oils as eco-friendly biopesticides? Challenges and constraints. Tr Plant Sci 21:1000-1007

Pavela R, Morshedloo MR, Mumivand H, Khorsand GJ, Karami A, Maggi F, Desneux N, Benelli G (2020) Phenolic monoterpenerich essential oils from Apiaceae and Lamiaceae species: insecticidal activity and safety evaluation on non-target earthworms. Entomol Gen 40:421-435

Pavlović M, Fantov T, Dević S, Marcelić Š, Franin K, Kos T (2019) The effectiveness of various measures for suppression of scale insect Planococcus ficus (Signoret) (Hemiptera: Coccoidea) on grapevine (Vitis vinifera L.) variety "Chardonnay" in the locality of Baštica, Zadar's county hinterland. In: Proceedings XV International Symposium on Scale Insect Studies, 17-20 June 2019, Zagreb, Croatia, p 72

Peschiutta ML, Pizzolitto RP, Ordano MA, Zaio YP, Zygadlo JA (2017) Laboratory evaluation of insecticidal activity of plant essential oils against the vine mealybug, Planococcus ficus. Vitis 56:79-83

Planes L, Catalán J, Tena A, Porcuna JL, Jacas JA, Izquierdo J, Urbaneja A (2013) Lethal and sublethal effects of spirotetramat on the mealybug destroyer, Cryptolaemus montrouzieri. J Pest Sci 86:321-327

Platt T, Stokwe NF, Malan AP (2018) Potential of local entomopathogenic nematodes for control of the vine mealybug, Planococcus ficus. S Afr J Enol Vitic 39:208-215

Platt T, Stokwe NF, Malan AP (2019) Foliar application of Steinernema yirgalemense to control Planococcus ficus: Assessing adjuvants to improve efficacy. S Afr J Enol Vitic 40:1-7

Prabhaker N, Gispert C, Castle SJ (2012) Baseline susceptibility of Planococcus ficus (Hemiptera: Pseudococcidae) from California to select insecticides. J Econ Entomol 105:1392-1400

Raspi A, Benelli G (2016) On the identity of Leucopis (Diptera Chamaemyiidae) described by Camillo Rondani: a revision of eight silver fly species. Bull Insectol 69:199-219

Ray HA, Hoy MA (2014) Effects of reduced-risk insecticides on three orchid pests and two predacious natural enemies. Fla Entomol 97:972-978

Ricciardi R, Lucchi A, Benelli G, Suckling DM (2019) Multiple mating in the citrophilous mealybug Pseudococcus calceolariae: implications for mating disruption. Insects 10:285

Romano D, Benelli G, Stefanini C, Desneux N, Ramirez-Romero R, Canale A, Lucchi A (2018) Behavioral asymmetries in the mealybug parasitoid Anagyrus sp. near pseudococci: does lateralized antennal tapping predict male mating success? J Pest Sci 91:341-349

Rondot Y, Reineke A (2018) Endophytic Beauveria bassiana in grapevine Vitis vinifera (L.) reduces infestation with piercing-sucking insects. Biol Control 116:82-89

Rotundo G, Tremblay E (1982) Hybridization and sex pheromone responses in two closely related mealybug species (Homoptera: Pseudococcidae). Syst Entomol 7:475-478
Rung A, Scheffer SJ, Evans G, Miller D (2008) Molecular identification of two closely related species of mealybugs of the genus Planococcus (Homoptera: Pseudococcidae). Ann Entomol Soc Am 101:525-532

Rust MK, Reierson DA, Klotz JH (2004) Delayed toxicity as a critical factor in the efficacy of aqueous baits for controlling argentine ants (Hyemoptera: Formicidae). J Econ Entomol 97:1017-1024

Rzaeva LM (1985) Parasites and predators of the grapevine mealybug (Planococcus ficus Signoret) and introduction of new entomophages to Eastern Transcaucasia. Izvestiya Akademii Nauk Azerbaidzan USSR. Biol Nauk 4:34-39 (in Russian)

Saccaggi DL, Kruger K, Pietersen G (2008) A multiplex PCR assay for the simultaneous identification of three mealybug species (Hemiptera: Pseudococcidae). Bull Entomol Res 98:27-33

Saeedi N, Damavandian MR, Moghanloo HD (2015) Effects of temperature on population growth parameters of Cryptolaemus montrouzieri (Coleoptera: Coccinellidae) reared on Planococcus citri (Homoptera: Pseudococcidae). Arthropods 4:78-89

Saljoqi AUR, Nasir M, Khan J et al (2014) The impact of temperature on biological and life table parameters of Cryptolaemus montrouzieri Mulsant (Coleoptera: Coccinellidae) fed on cotton mealybug, Phenacoccus solenopsis Tinsley. Pak J Zool 46:1591-1597

Santoiemma G, Tonina L, Marini L, Duso C, Mori N (2020) Integrated management of Drosophila suzukii in sweet cherry orchards. Entomol Gen 40:297-305

Schulze-Sylvester M, Corronca JA, Paris CI (2018) Growing industries, growing invasions? The case of the Argentine ant in vineyards of northern Argentina. Insects 9:11

Schwartz A (1988) Efficacy of trunk barriers for the control of key pests on trellised grapevines. S Afr J Enol Vitic 16:16-18

Serra G, Lentini A, Verdinelli M, Delrio G (2006) Effects of cover crop management on grape pests in a Mediterranean environment. IOBC-WPRS Bull 29(11):209-214

Shannag HK, Capinera JL (2018) Comparative effects of two novel Betaproteobacteria-based insecticides on Myzus persicae (Hemiptera: Aphididae) and Phenacoccus madeirensis (Hemiptera: Pseudococcidae). Fla Entomol 101:212-218

Shapira I, Gavish-Regev E, Sharon R, Harari AR, Kishinevsky M, Keasar T (2018) Habitat use by crop pests and natural enemies in a Mediterranean vineyard agroecosystem. Agric Ecosyst Environ 267:109-118

Shapira I, Keasar T, Harari AR, Gavish-Regev E, Kishinevsky M, Steinitz H et al (2018) Does mating disruption of Planococcus ficus and Lobesia botrana affect the diversity, abundance and composition of natural enemies in Israeli vineyards? Pest Manag Sci 74:1837-1844

Sharley DJ, Hoffmann AA, Thomson LJ (2008) The effects of soil tillage on beneficial invertebrates within the vineyard. Agric For Entomol 10:233-243

Sharma L, Gonçalves F, Oliveira I, Torres L, Marques G (2018) Insectassociated fungi from naturally mycosed vine mealybug Planococcus ficus (Signoret) (Hemiptera: Pseudococcidae). Biocontrol Sci Technol 28:122-141

Sharon R, Zahavi T, Sokolsky T, Sofer-Arad C, Tomer M, Kedoshim R, Harari AR (2016) Mating disruption method against the vine mealybug, Planococcus ficus: effect of sequential treatments on infested vines. Entomol Exp Appl 161:65-69

Sharon R, Zahavi T, Sokolsky T, Sofer-Arad C, Tomer M, Almog A, Harari A (2017) Year-round mating disruption in vineyards overcomes the vine mealybug (Planococcus ficus) population's build-up during the warming winters. Proceedings "Future IPM 3.0 towards a sustainable agriculture", 15-20 October 2017, Riva del Garda, Italy, pp 192-194 
Silverman J, Roulston TH (2001) Acceptance and intake of gel and liquid sucrose compositions by the argentine ant (Hymenoptera: Formicidae). J Econ Entomol 94:511-515

Sime KR, Daane KM (2014) A comparison of two parasitoids (Hymenoptera: Encyrtidae) of the vine mealybug: rapid, non-discriminatory oviposition is favored when ants tend the host. Environ Entomol 43:995-1002

Soares MA, Campos MR, Passos LC, Carvalho GA, Haro MM, Lavoir AV, Biondi A, Zappala L, Desneux N, (2019) Botanical insecticide and natural enemies: a potential combination for pest management against Tuta absoluta. J Pest Sci 92:1433-1443

Soares MA, Carvalho GA, Campos MR, Passos LC, Haro MM, Lavoir AV, Biondi A, Zappala L, Desneux N (2020) Detrimental sublethal effects hamper the effective use of natural and chemical pesticides in combination with a key natural enemy of on tomato. Pest Manag Sci 76:3551-3559

Soler R, Scatoni I, Núñez S (1997) Bioecología y estrategia de control del "Chanchito blanco" de la vid en la zona sur del Uruguay. Convenio INIA-FUCREA, p 16

Sterk G, Hassan SA, Baillod M, Bakker F, Bigler F, Blümel S et al (1999) Results of the seventh joint pesticide testing programme carried out by the IOBC/WPRS-Working Group 'Pesticides and Beneficial Organisms.' Biocontrol 44:99-117

Suckling DM, Peck RW, Manning LM, Stringer LD, Cappadonna J, El-Sayed AM, (2008) Pheromone disruption of Argentine ant trail integrity. J Chem Ecol 34:1602-1609

Suckling DM, Stringer LD, Bunn B, El-Sayed AM, Meer RKV (2010) Trail pheromone disruption of red imported fire ant. J Chem Ecol 36:744-750

Suma P, Mansour R, Russo A, La Torre I, Bugila AAA, Franco JC (2012) Encapsulation rates of the parasitoid Anagyrus sp. nr. pseudococci, by three mealybug species (Hemiptera: Pseudococcidae). Phytoparasitica 40:11-16

Tabata J (2020) Sex pheromones of mealybugs: Implications for evolution and application. In: Ishikawa Y (ed) Insect sex pheromone research and beyond. Springer, Singapore, pp 35-59

Tacoli F, Bell VA, Cargnus E, Pavan F (2018) Insecticidal activity of natural products against vineyard mealybugs (Hemiptera: Pseudococcidae). Crop Prot 111:50-57

Tacoli F, Pavan F, Cargnus E, Tilatti E, Pozzebon A, Zandigiacomo $P$ (2017) Efficacy and mode of action of kaolin in the control of Empoasca vitis and Zygina rhamni (Hemiptera: Cicadellidae) in vineyards. J Econ Entomol 110:1164-1178

Tanaka Y, Nishisue K, Sunamura E, Suzuki S, Sakamoto H, Fukumoto T, Terayama M, Tatsuki S (2009) Trail-following disruption in the invasive Argentine ant with a synthetic trail pheromone component (Z)-9-hexadecenal. Sociobiology 54:139-152

Tanne E, Ben-Dov Y, Raccah B (1989) Transmission of the corkybark disease by the mealybug Planococcus ficus. Phytoparasitica 17:55-55

Taskin E, Lamaj F, Verrastro V, Baldacchino F (2014) Laboratory efficacy of natural substances on Planococcus ficus (Sign.) and their impact on its two natural enemies. In: Proceedings of the Fifth International Scientific Agricultural Symposium "Agrosym", 23-26 October 2014, Jahorina, Bosnia and Herzegovina, pp 23-26

Thomson LJ, Hoffmann AA (2009) Vegetation increases the abundance of natural enemies in vineyards. Biol Control 49:259-269

Thomson LJ, Hoffmann AA (2013) Spatial scale of benefits from adjacent woody vegetation on natural enemies within vineyards. Biol Control 64:57-65

Timm AE, Reineke A (2014) First insights into grapevine transcriptional responses as a result of vine mealybug Planococcus ficus feeding. Arthropod-Plant Interact 8:495-505

Tingle CCD, Copland MJW (1988) Predicting development of the mealybug parasitoids Anagyrus pseudococci, Leptomastix dactylopii and Leptomastidae abnormis under glasshouse conditions. Entomol Exp Appl 46:19-28

Todorov K (2018) New organic mineral insecticide introduced against the vine mealybugs and other insects. Wine Business Daily News. https://www.winebusiness.com/news/?go=getArticle \&dataId=202349 Accessed 25 August 2020

Tollerup KE, Rust MK, Dorschner KW, Phillips P, Klotz JH (2004) Low-toxicity baits control ants in citrus orchards and grape vineyards. Calif Agric 58:213-217

Tollerup KE (2007) Managing populations of the vine mealybug, Planococcus ficus (Hemiptera: Pseudococcidae), in Coachella Valley vineyards using inundative releases of the parasitoid, Anagyrus pseudococci (Hymenoptera: Encyrtidae), and baits to control the field ant, Formica perpilosa (Hymenoptera: Formicidae). $\mathrm{Ph}$.D. thesis dissertation, University of California

Triapitsyn SV, Gonzàlez D, Vickerman DB, Noyes JS, White EB (2007) Morphological, biological, and molecular comparisons among the different geographical populations of Anagyrus pseudococci (Hymenoptera: Encyrtidae), parasitoids of Planococcus spp. (Hemiptera: Pseudococcidae), with notes on Anagyrus dactylopii. Biol Control 41:14-24

Triapitsyn SV, Gonzalez D, White EB, Vickerman DB, Noyes JS, Hoddle MS (2005) Two different species under one name: morphological, biological, and molecular comparison between the different geographical populations of Anagyrus pseudococci, a well-known agent used in biological control of citrus and vine mealybugs. In: Proceedings Second International Symposium on Biological Control of Arthropods, September 12-16 2005, Davos, Switzerland, p 131

Trjapitzin VA, Triapitsyn SV (2002) A new species of Neoplatycerus (Hymenoptera: Encyrtidae) from Egypt, parasitoid of the vine mealybug, Planococcus ficus (Homoptera: Pseudococcidae). Entomol News 113:203-210

Trjapitzin VA (1989) Parasitic Hymenoptera of the fam. Encyrtidae of Palaearctics. Opredeliteli po faune SSSR, 158. Leningrad, Nauka, p 489 (In Russian)

Trjapitzyn SV, Trjapitzyn VA (1999) Parasitoids of the mealybugs on cultivated grapes in Argentina, with description of a new species of the genus Aenasius Walker (Hymenoptera, Encyrtidae). Entomol Obozr 76:174-179 (in Russian)

Tsai C-W, Rowhani A, Golino DA, Daane KM, Almeida RPP (2010) Mealybug transmission of grapevine leafroll viruses: An analysis of virus-vector specificity. Phytopathology 100:830-834

Urban AJ (1985) Unpublished final report, The integrated control of vine mealybug, Planococcus ficus (Signoret) on vines. Plant Protection Research Institute, Polkadrive, Stellenbosch, Private Bag X5017, Stellenbosch, South Africa

Urbina A, Verdugo JA, López E, Bergmann J, Zaviezo T, Flores MF (2018) Searching behavior of Cryptolaemus montrouzieri (Coleoptera: Coccinellidae) in response to mealybug sex pheromones. J Econ Entomol 111:1996-1999

Varela LG, Smith RJ, Battany M, Bentley W (2006) Which mealybug is it, why should you care? Practical Winery \& Vineyard JanuaryFebruary 2006:1-6

Varikou K, Birouraki A, Bagis N, Kontodimas DC (2010) Effect of temperature on the development and longevity of Planococcus ficus (Hemiptera: Pseudococcidae). Ann Entomol Soc Am 103:943-948

Venkatesan T, Jalali SK, Ramya SL, Prathibha M (2016) Insecticide resistance and its management in mealybugs. In: Mani M, Shivaraju C (eds) Mealybugs and their management in agricultural and horticultural crops. Springer, New Delhi, pp 223-229

Le Vieux PD, Malan AP (2013) An overview of the vine mealybug (Planococcus ficus) in South African vineyards and the use of entomopathogenic nematodes as potential biocontrol agent. S Afr J Enol Vitic 34:108-118 
Le Vieux PD, Malan AP (2015) Prospects for using entomopathogenic nematodes to control the vine mealybug, Planococcus ficus, in South African vineyards. S Afr J Enol Vitic 36:59-70

Vincent C, Isaacs R, Bostanian NJ, Lasnier J (2012) Principles of arthropod pest management in vineyards. In: Bostanian N, Vincent $\mathrm{C}$, Isaacs $\mathrm{R}$ (eds) Arthropod management in vineyards: Pests, approaches, and future directions. Springer, Dordrecht, pp 1-16

Walton VM, Daane KM, Addison P (2012) Biological control of arthropods and its application in vineyards. In: Bostanian N, Vincent C, Isaacs R (eds) Arthropod management in vineyards: Pests, approaches, and future directions. Springer, Dordrecht, pp 139-157

Walton VM, Daane KM, Bentley WJ, Millar JG, Larsen TE, Malakar-Kuenen R (2006) Pheromone-based mating disruption of Planococcus ficus (Hemiptera: Pseudococcidae) in California vineyards. J Econ Entomol 99:1280-1290

Walton VM, Daane KM, Pringle KL (2004) Monitoring Planococcus ficus in South African vineyards with sex pheromone-baited traps. Crop Prot 23:1089-1096

Walton VM, Pringle KL (2004a) A survey of mealybugs and associated natural enemies in vineyards in the Western Cape Province, South Africa. S Afr J Enol Vitic 25:23-25

Walton VM, Pringle KL (2004b) Vine mealybug, Planococcus ficus (Sign.) (Hemiptera: Pseudococcidae), a key pest in South African vineyards. A review. S Afr J Enol Vitic 25:54-62

Walton VM, Pringle KL (2005) Developmental biology of vine mealybug, Planococcus ficus (Signoret) (Homoptera: Pseudococcidae), and its parasitoid Coccidoxenoides perminutus (Timberlake) (Hymenoptera: Encyrtidae). Afr Entomol 13:143-147

Walton VM (2003) Development of an integrated pest management system for vine mealybug, Planococcus ficus (Signoret), in vineyards in the Western Cape Province, South Africa. Ph.D. Thesis dissertation, Stellenbosch University

Walton VM, Pringle KL (2003) Evaluating effectiveness of mass release of the vine mealybug (Planococcus ficus) parasitoid Coccidoxenoides peregrinus in western Cape Province vineyards, South Africa. In: Proceedings of the $1^{\text {st }}$ International Symposium on Biological Control of Arthropods, 14-18 January 2002, Honolulu, USA, pp 524-532

Waterworth RA, Wright IM, Millar JG (2011) Reproductive biology of three cosmopolitan mealybug (Hemiptera: Pseudococcidae) species, Pseudococcus longispinus, Pseudococcus viburni, and Planococcus ficus. Ann Entomol Soc Am 104:49-260

Way MJ (1963) Mutualism between ants and honeydew-producing Homopterans. Annu Rev Entomol 8:307-344
Westermann FL, Bell VA, Suckling DM, Lester PJ (2016) Synthetic pheromones as a management technique - dispensers reduce Linepithema humile activity in a commercial vineyard. Pest Manag Sci 72:719-724

Whitehead VB (1957) A study of the predators and parasites of Planococcus citri (Risso) (Homoptera) on vines in the Western Cape Province. Thesis, Rhodes University, South Africa

Williams DJ, Granara de Willink MC (1992) Mealybugs of central and south America. CAB International, Wallingford

Wilson H, Daane KM (2017) Review of ecologically-based pest management in California Vineyards. Insects 8:108

Wohlfarter M, Addison P (2014) Life table study of Anagyrus sp. nr. pseudococci (Girault) (Hymenoptera: Encyrtidae) on its host, Planococcus ficus (Signoret) (Hemiptera: Pseudococcidae). Afr Entomol 22:250-256

Wood BR, Tedders WL, Reilly CC (1988) Sooty mold fungus on pecan foliage suppresses light penetration and net photosynthesis. HortScience 23:851-853

Yasnosh VA (1999) Observations on some mealybugs (Coccinea: Pseudococcidae) and their natural enemies on arborate plants in the Republic of Georgia. Entomologica 33:435-440

Yasnosh V, Rtskhiladze M, Tabatadze E (2001) Coccids (Hemiptera, Coccinea) and their natural enemies in the vineyards of Georgia: present situation. Boll Zool Agr Bachic 33:351-355

Zada A, Dunkelblum E, Assael F, Franco JC, da Silva EB, Protasov A, Mendel Z (2008) Attraction of Planococcus ficus males to racemic and chiral pheromone baits: flight activity and bait longevity. J Appl Entomol 132:480-489

Zada A, Dunkelblum E, Assael F, Harel M, Cojocaru M, Mendel Z (2003) Sex pheromone of the vine mealybug, Planococcus ficus in Israel: occurrence of a second component in a mass-reared population. J Chem Ecol 29:977-988

Zhou A, Lu Y, Zeng L, Xu Y, Liang G (2012) Does mutualism drive the invasion of two alien species? The case of Solenopsis invicta and Phenacoccus solenopsis. PLoS ONE 7(7):e41856

Zina V, Franco JC (2015) Ecological diversity of ants (Hymenoptera, Formicidae) in Tapada da Ajuda, Portugal. Iberomyrmex $7: 17-23$

Zinna G (1960) Ricerche sugli insetti entomofagi I. Specializzazione entomoparassitica negli Encyrtidae. Studio morfologico, etologico e fisiologico del Leptomastix dactylopii Howard. Boll Lab Ent Agr Fillipo Silvestri 18:1-148

Publisher's Note Springer Nature remains neutral with regard to jurisdictional claims in published maps and institutional affiliations. 